GUIDELINES

\title{
Guidelines for the management of patients with pancreatic cancer periampullary and ampullary carcinomas
}

\section{Pancreatic Section of the British Society of Gastroenterology, Pancreatic Society of Great Britain and Ireland, Association of Upper Gastrointestinal Surgeons of Great Britain and Ireland, Royal College of Pathologists, Special Interest Group for Gastro-Intestinal Radiology}

Gut 2005;54(Suppl V):v1-v16. doi: 10.1136/gut.2004.057059

\subsection{GUIDELINES - SUMMARY DOCUMENT}

The following recommendations are introduced by brief statements which summarise the evidence and discussion presented in the relevant section of the full text of the guidelines.

\subsection{Incidence, mortality rates, and aetiology \\ Pancreatic cancer is an important health problem for which no simple screening test is available. The strongest aetiological association is with cigarette smoking, although at risk groups include patients with chronic pancreatitis, adult onset diabetes of less than two years' duration, hereditary pancreatitis, familial pancreatic can- cers, and certain familial cancer syndromes. Periampullary cancers are a feature of familial adenomatous polyposis.}

\section{Recommendations}

- Continued health education to reduce tobacco consumption should lower the risk of developing pancreatic carcinoma (grade B).

- All patients at increased inherited risk of pancreatic cancer should be referred to a specialist centre offering specialist clinical advice and genetic counselling and appropriate genetic testing (grade B).

- Secondary screening for pancreatic cancer in high risk cases should be carried out as part of an investigational programme coordinated through specialist centres (grade B).

- Examination and biopsy of the periampullary region is important in patients with longstanding familial adenomatous polyposis. The frequency of endoscopy is determined by the severity of the duodenal polyposis (grade B).

- Patients with stage 4 duodenal polyposis who are fit for surgery should be offered resection (grade B).

Correspondence to: Mr C D Johnson, University Surgical Unit, Mail point 816, Southampton General Hospital, Southampton SO'16 6YD, UK; c.d.johnson@soton. ac.uk lymph node metastases. Variants of ductal carcinomas and other malignant tumours of the pancreas are rare.

\section{Recommendations}

- Proper recognition of variants of ductal carcinomas and other malignant tumours of the pancreas require specialist pathological expertise (grade C).

- The minimum data set proposed by the Royal College of Pathologists (see appendix for details) should be used for reporting histological examination of pancreatic resection specimens (grade $\mathrm{C}$ ).

\subsection{Clinical features}

In the majority of patients, the clinical diagnosis is fairly straightforward, although there are no positive clinical features which clearly identify a patient group with potentially curable disease. There are associated conditions, such as late onset diabetes mellitus or an unexplained attack of acute pancreatitis, which may point to an underlying cancer. A number of clinical features (persistent back pain, marked and rapid weight loss, abdominal mass, ascites, and supraclavicular lymphadenopathy) usually indicate an incurable situation

\section{Recommendations}

- The diagnosis of pancreatic cancer should be considered in patients with adult onset diabetes who have no predisposing features or family history of diabetes (grade B).

- Pancreatic cancer should be excluded during the investigation of patients who have had an unexplained episode of acute pancreatitis (grade B).

Abbreviations: $C T$, computed tomography; $M R$, magnetic resonance; $M R C P$, magnetic resonance cholangiopancreatography; ERCP, endoscopic retrograde cholangiopancreatography; MRA, magnetic resonance angiography; FAP, familial adenomatous polyposis; EUS, endosonography; 5-FU, 5-fluorouracil
Most pancreatic cancers are of ductal origin and present at a stage when they are locally advanced, and exhibit vascular invasion and 


\subsection{Investigations}

The workup of patients with suspected pancreatic cancer should logically focus initially on establishment of the diagnosis and an assessment of the patient's fitness to undergo potentially curative treatment. In selected patients, further investigation involves tumour staging and the assessment of local respectability.

\section{Recommendations}

- Clinical presentation suggesting cancer of the pancreas should lead without delay to ultrasound of the liver, bile duct, and pancreas (grade B).

- When the diagnosis of pancreatic malignancy is suspected from clinical symptoms and/or abdominal ultrasound findings, the selective use of computerised tomography $(\mathrm{CT})$, endoscopic retrograde cholangiopancreatography (ERCP), and/or magnetic resonance $(M R)$, including magnetic resonance cholangiopancreatography (MRCP) and occasionally magnetic resonance angiography (MRA), will accurately delineate tumour size, infiltration, and the presence of metastatic disease in the majority of cases (grade B).

- Where available, endosonography and/or laparoscopy with laparoscopic ultrasonography may be appropriate in selected cases (grade B).

\subsection{Tissue diagnosis}

\section{Recommendations}

- Attempts should be made to obtain a tissue diagnosis during the course of investigative endoscopic procedures (grade C).

- Failure to obtain histological confirmation of a suspected diagnosis of malignancy does not exclude the presence of a tumour, and should not delay appropriate surgical treatment (grade C).

- Efforts should be made to obtain a tissue diagnosis in patients selected for palliative forms of therapy (grade C).

- Transperitoneal techniques to obtain a tissue diagnosis have limited sensitivity in patients with potentially resectable tumours and should be avoided in such patients (grade $\mathrm{C}$ ).

\subsection{Treatment}

This largely centres around palliative surgery undertaken to relieve symptoms, resectional surgery with intent to cure, and endoscopic or percutaneous biliary stenting to relieve jaundice. There is an increasing use of chemotherapy and radiotherapy, both as palliative treatments as well as in an adjuvant setting in conjunction with surgery, although much of this practice is not evidence based. Appropriately designed multicentre clinical trials remain essential.

\section{Recommendations}

\section{Stent or surgical palliation}

- Most patients requiring relief of obstructive jaundice will be adequately treated by placement of a plastic stent; surgical bypass may be preferred in patients likely to survive more than six months (grade A).

- Duodenal obstruction should be treated surgically (grade C).

\section{Stent insertion}

- Endoscopic stent placement is preferable to transhepatic stenting (grade A).

- After failure of endoscopic stent placement, percutaneous placement of a self expanding metal stent, or a combined radiological/endoscopic approach, will increase the number of patients who can be successfully stented (grade B).

- Both plastic and self expanding metal stents are effective in achieving biliary drainage but require further development (grade A). Currently, the choice between these stents depends on clinical factors, local availability, and local expertise (grade C).

- If a stent is placed prior to surgery, this should be of the plastic type and it should be placed endoscopically. Self expanding metal stents should not be inserted in patients who are likely to proceed to resection (grade C).

\section{Resectional surgery}

- This should be confined to specialist centres, to increase resection rates and reduce hospital morbidity and mortality (grade B).

- Pancreaticoduodenectomy (with or without pylorus preservation) is the most appropriate resectional procedure for tumours of the pancreatic head (grade B).

- Extended resections involving the portal vein or total pancreatectomy may be required in some cases but do not increase survival when carried out routinely (grade B).

- Resection in the presence of preoperative detection of portal vein encasement is rarely justified (grade C).

- Percutaneous biliary drainage prior to resection in jaundiced patients does not improve surgical outcome and may increase the risk of infective complications (grade A).

- Left sided resection (with splenectomy) is appropriate for localised carcinomas of the body and tail of the pancreas. Involvement of the splenic vein or artery is not in itself a contraindication to such resection. (grade B)

\section{Palliative surgery}

- Duodenal bypass should be used during palliative surgery (grade B).

- Biliary bypass should be constructed with the bile duct in preference to the gall bladder (grade B).

\section{Non-surgical therapies}

- Adjuvant or neoadjuvant therapies in conjunction with surgery should only be given in the context of a clinical trial (grade A).

- If chemotherapy is used for palliation, gemcitabine single agent treatment is recommended (grade A).

- Therapy with novel treatments should only be offered to patients within clinical trials (grade C). 
Relief of pancreatic pain/palliative care

- Patients should have access to palliative care specialists (grade C).

- Pain relief should be achieved using a progressive analgesic ladder (grade B).

- Neurolytic coeliac plexus block is effective for the treatment and prevention of pain. Its use should be considered at the time of palliative surgery, or by percutaneous or endoscopic approach in non-surgical patients (grade A).

- Chemoradiation should be considered for severe pain (grade B).

- Pancreatic enzyme supplements should be used to maintain weight and increase quality of life (grade A).

- Attention to dietary intake and the use of specific nutritional supplements may improve well being (grade B).

\subsection{Organisation of services}

The provision of effective services requires local cancer units as well as specialist centres.

\subsubsection{Cancer units}

These require sufficient diagnostic and therapeutic facilities to establish a likely diagnosis, assess the patient's overall level of fitness to withstand potentially curative forms of treatment, and provide appropriate therapeutic facilities to ensure that adequate symptom palliation can be achieved.

Until services can be reorganised as specified by the NHS Executive, it is accepted that at some cancer units a specialist pancreatic surgeon may be available, and if the case load is sufficient, then resectional surgery may be justified on an interim basis This is only appropriate if the cancer unit has been approved to undertake resections by the Regional Upper Gastro-Intestinal and/or Hepato-Biliary-Pancreatic Cancer Network Group.

The minimum requirements for a cancer unit are:

- An integrated system of clinical care involving medical and surgical gastroenterology, clinical oncology, radiology, and pathology.

- Adequate radiological facilities to establish a diagnosis and the likely stage of disease. This should include abdominal ultrasound and a whole body imaging technique (CT or MRI). Guided biopsy techniques should be available for patients considered not suitable for surgical resection.

- Therapeutic facilities should include both endoscopic and radiological biliary stenting and, at least on an interim basis, facilities for surgical palliation.

- A variety of ancillary services are required, including palliative care, acute and chronic pain services, and clinical nutrition.

Local cancer units should provide guidance to primary health care physicians to ensure adequate patient referral. The following patient groups merit general practitioner referral to a local cancer unit:

- Obstructive jaundice.

- Unexplained weight loss.

- Unexplained gastrointestinal bleeding or iron deficiency anaemia thought to be of gastrointestinal origin in the absence of an upper gastrointestinal or colorectal cause.

- Unexplained upper abdominal or back pain.

- Unexplained steatorrhoea
- "Idiopathic" acute pancreatitis (no gallstones, no alcohol) in patients over 50 years of age.

- Unexplained diabetes in patients over 50 years of age (no family history, obesity, or steroids).

\subsubsection{Specialist centres}

These require all of the services provided by cancer units, with increased facilities for precise pretreatment staging of disease with particular emphasis on assessment of resectability, increased therapeutic resources, and adequate surgical expertise for pancreatic resections. They also require additional services in histopathology, intensive care, palliative care, and medical and clinical oncology, along with facilities for the organisation and conduct of local, national, and international trials. The Regional Cancer Network Group plan must ensure the timely establishment of the Regional Pancreas Tumour Centre based on a minimum of two million population that will undertake all pancreatic cancer resections in accordance with the National plans.

Specialist centres require all of the services provided at cancer units with further additions. These are:

- Facilities to include the majority of: spiral or multislice CT, MRI, endoscopic ultrasonography, and laparoscopic ultrasonography for precise pretreatment staging of disease with particular emphasis on assessment of resectability.

- Increased therapeutic resources, including expertise in radiological and endoscopic intervention and adequate surgical expertise for pancreatic resections.

- Additional services in histopathology (see pathology reporting), intensive care, palliative care, and oncology.

- Facilities for the organisation and conduct of local, national, and international trials, evaluating new modalities for diagnosis and treatment as well as involvement in basic science research in pancreatic cancer.

\subsection{Audit and audit standards}

Comprehensive clinical audit is essential. The minimum data set for the performance of an effective audit process is outlined below. The data set required in patients undergoing resection and the necessary information to complete this appropriately appear as an appendix.

\subsubsection{Minimum data set for audit}

- Accurate demographic information on all diagnosed cases.

- Duration of symptoms until first consultation.

- Duration from first consultation to referral to local cancer unit.

- Duration from date of referral to date of treatment.

- Accurate information on stage of disease involving the use of standardised histopathological assessments.

- Treatments received (the time from initial to definitive treatment should not exceed six weeks).

- Duration of hospital stays.

- Complications of treatment.

- Duration of survival.

- Quality of life assessments using validated instruments (for example, EORTC QLQ-C30) with a pancreatic cancer specific module (for example, QLQ PAN26), should be applied to all patients involved in prospective clinical trials.

The following standards are appropriate for clinical audit.

- Cancer units should respond to general practitioner requests within two weeks and specialist centres should 
respond to cancer unit referrals within a further two weeks.

- A full minimum data set should be available for all patients

- Resection rate in unselected patients should be more than $10 \%$, and associated hospital mortality rate after pancreatic resection should be less than $10 \%$.

\subsection{PREPARATION OF THE GUIDELINES}

This document covers a variety of areas which impact upon the production of clinical guidelines. The conclusions drawn at the end of each subsection have been used to generate a summary document. Due to considerable clinical similarities, pancreatic, periampullary, and ampullary cancers have been considered together.

These guidelines have been produced to help clinicians in the management of pancreatic and periampullary cancers. They were developed at the request of the Clinical Services Section of the British Society of Gastroenterology, with the support and endorsement of the Pancreatic Society of Great Britain and Ireland, the Association of Upper Gastrointestinal Surgeons of Great Britain and Ireland, the Royal College of Pathologists, and the Special Interest Group for GastroIntestinal Radiology. The guidelines were drawn up by a drafting committee under the Chairmanship of Professor Derek Alderson. The final document was prepared by a small writing committee and incorporates comments from members of the drafting committee and other interseted parties.

The evidence and recommendations have been assessed using a system designed by the Health Services Research Unit, University of Aberdeen. This system is summarised below.

\subsection{Grading of evidence}

- Grade Ia: meta-analysis of randomised controlled trials (RCT).

- Grade Ib: at least one RCT.

- Grade IIa: at least one well designed controlled study without randomisation.

- Grade IIb: at least one other type of well designed quasiexperimental study.

- Grade III: well designed non-experimental descriptive studies (for example, comparative, correlation, case studies).

- Grade IV: expert committee reports or opinions and/or clinical experiences of respected authorities.

\subsection{Grading of recommendations}

- Grade A: at least one RCT (Ia, Ib).

- Grade B: well conducted clinical studies (IIa, IIb, III).

- Grade C: respected opinions but absence of directly applicable good quality clinical studies (IV).

As the management of pancreatic cancer continues to evolve, new evidence will inevitably become available at regular intervals so that guidelines will need to be updated accordingly. The drafting committee considers that these guidelines will require revision within five years.

\subsection{INCIDENCE AND MORTALITY RATES}

The incidence of pancreatic cancer appears to have increased steadily in many countries for most of the 20th century. Mortality doubled in the UK between 1930 and 1970, but has risen much more slowly since then and it is the sixth most common cancer death in this country. ${ }^{12}$ The incidence is higher in Western or industrialised countries in general. ${ }^{3}$
Pancreatic cancer is rare before the age of 45 years and $80 \%$ of cases occur in the 60-80 year age group. ${ }^{45}$

Although there are considerable limitations to interpretation of epidemiological data, ${ }^{6}$ a study in the West Midlands indicated an age standardised incidence between 1960 and 1984 of approximately 10 cases per 100000 population. $^{7}$ There seems to have been some levelling of the annual incidence reported in this and other series. ${ }^{8} 9$ Because the five year survival of this condition is so poor, incidence and mortality rates are virtually identical.

Pancreatic cancer has been more common in men than women but this is now beginning to change. In the USA, the Surveillance, Epidemiology, and End Results $(\text { SEER })^{10}$ programme has shown a fall in the total incidence of pancreatic cancer from 12.3 per 100000 in 1973 to 10.7 per 100000 in $1999 .{ }^{10}$ During the same period, the decline in rates for men was from 16.1 per 100000 population to 12.1 per 100000 , and for women from 9.6 per 100000 to 9.5 per 100000 , respectively.

Other periampullary tumours (of the ampulla, lower common bile duct, or duodenum) present with similar symptoms and signs to pancreatic cancer; without careful histological evaluation the differential diagnosis of tumour type may be impossible. The numbers of periampullary cancers are lower than pancreatic cancers, but they are more often resectable, so as many as half of pancreatic resections are for these periampullary tumours.

\subsection{AETIOLOGY}

The causes of pancreatic and periampullary cancer are not known. A variety of risk factors have been identified. The risk factor most consistently identified is cigarette smoking which may account for approximately $25-30 \%$ of cases. ${ }^{11-20}$

Other factors including diet (high fat and protein, low fruit and vegetable intake), coffee consumption, alcohol, occupation, and the effects of other diseases such as diabetes mellitus, pernicious anaemia, chronic pancreatitis, cholelithiasis, and previous gastric surgery, have also been studied in detail. Of these, only in chronic pancreatitis and adult onset diabetes of less than two years' duration does there seem to be clear evidence of an increased risk of pancreatic cancer. ${ }^{1921-23}$ Chronic pancreatitis is associated with an increased risk of cancer of the order of 5-15-fold. ${ }^{19}$ Hereditary pancreatitis is associated with a $50-70$-fold risk and a cumulative lifetime risk to the age of 75 years of $40 \%{ }^{24} 25$

Pancreatic cancer may also occur in three other settings in which there is an inherited predisposition. Firstly, there appears to be an inherited component to pancreatic cancer in up to $10 \%$ of patients with pancreatic cancer in the absence of familial pancreatic cancer and other cancer syndromes. ${ }^{26}{ }^{27}$ Secondly, there is an increased incidence of pancreatic cancer in individuals from families with familial pancreatic cancer in which the disease appears to be transmitted in an autosomal dominant manner with impaired penetrance. Two recent studies have shown that approximately $17-19 \%$ of these families may have disease causing BRCA2 mutations in both Jewish and non-Jewish populations. ${ }^{28}{ }^{29}$ Thirdly, an increased risk of pancreatic cancer may occur as part of another cancer syndrome, including familial atypical multiple mole melanoma, Peutz-Jeghers syndrome, hereditary non-polyposis colorectal carcinoma (HNPCC), familial breast-ovarian cancer syndromes, and familial adenomatous polyposis (FAP) but probably not Li-Fraumeni syndrome..$^{30-36}$

The diagnosis and management of genetic predispositions to pancreatic cancer are developing rapidly. Consensus Guidelines of the International Association of Pancreatology advise that patients with an inherited predisposition to pancreatic cancer should be referred to specialist centres 
capable of providing expert clinical assessment of pancreatic diseases, genetic counselling, and advice on secondary screening. ${ }^{37}$ In the UK, the national co-coordinating centre for secondary screening for pancreatic cancer is the European Registry of Hereditary Pancreatic Diseases (EUROPAC). ${ }^{38}$

\subsection{Periampullary cancers}

Periampullary cancers can be broadly considered as those tumours arising out of or within $1 \mathrm{~cm}$ of the papilla of Vater and include ampullary, pancreatic, bile duct, and duodenal cancer. There is a high incidence of these tumours in patients with FAP. ${ }^{35} 3940$ The median interval between colectomy for FAP and the development of upper gastrointestinal cancer is 22 years $^{39}$ and cancer is often preceded by ampullary or duodenal adenomas ${ }^{39}{ }^{40}$ or arises in an adenoma. ${ }^{41}$ The frequency of periampullary neoplasms in FAP patients is sufficient to warrant a policy of regular duodenoscopy and biopsy of suspicious lesions. Duodenoscopy should be started when colorectal polyps have been diagnosed, and repeated at intervals of five years (stage 0/1 polyposis), three years (stage 2 polyposis), and one or two years for patients with stage 3 duodenal polyposis. ${ }^{42}$ Patients with stage 4 polyposis should be advised to have surgical resection by pylorus preserving pancreaticoduodenectomy. ${ }^{42}$

\section{Conclusions}

- Pancreatic cancer is an important health problem.

- No simple screening test is available for the general population.

- With an increasingly elderly population, there can be no expectation of a marked reduction in incidence.

- The strongest aetiological association is with cigarette smoking.

- At risk groups include:

- Patients with chronic pancreatitis.

- Adult onset diabetes of less than two years' duration.

- Patients with hereditary pancreatitis, familial pancreatic cancer, and certain other cancer family syndromes, notably ovarian and breast cancer syndrome and the familial multiple mole melanoma syndrome.

- Periampullary cancer is a feature of familial adenomatous polyposis

\section{Recommendations based on epidemiology}

- Continued health education to reduce tobacco consumption should lower the risk of developing pancreatic carcinoma (grade B).

- All patients at increased inherited risk of pancreatic cancer should be referred to a specialist centre offering specialist clinical advice and genetic counselling and appropriate genetic testing (grade B).

- Secondary screening for pancreatic cancer in high risk cases should be carried out as part of an investigational programme coordinated through specialist centres (grade B).

- Examination and biopsy of the periampullary region is important in patients with longstanding familial adenomatous polyposis. The frequency of endoscopy is determined by the severity of the duodenal polyposis (grade B).

- Patients with stage 4 duodenal polyposis who are fit for surgery should be offered resection (grade B).

\subsection{PATHOLOGY}

Although a variety of exocrine pancreatic tumours exist, by far the most common is ductal adenocarcinoma which accounts for well over $90 \%$ of all tumours. In surgical resection series, $80-90 \%$ occur in the head of the gland. ${ }^{43}$ Lymph node metastases are common and are present at the time of surgery in $40-75 \%$ of primary tumours less than $2 \mathrm{~cm}$ in diameter. ${ }^{43}$ Perineural infiltration and vascular invasion are both frequently seen in resection specimens.

A variety of other exocrine tumours arise from the pancreas (see appendix for details) and because of their rarity they often require specialist pathological interpretation. Some, such as serous and mucinous tumours, intraductal-mucinous tumour, and solid-pseudopapillary tumour, have a very much better prognosis than pancreatic adenocarcinoma. ${ }^{44}$ Endocrine tumours and lymphomas can be confused clinically and radiologically with pancreatic carcinoma. Some endocrine tumours have characteristic presentations such as insulinoma, glucagonoma, and gastrinoma. Management of these hormonally active neoplasms lies outside the scope of this document but the possibility of a clinically silent endocrine tumour should be considered when a mass is identified in the absence of other clinical features characteristic of pancreatic cancer. A tissue diagnosis is thus important in the management of a patient with a mass in the pancreas.

\section{Conclusions}

- Most pancreatic carcinomas are of ductal origin. They are usually locally advanced, exhibit vascular invasion, and lymph node metastases.

- Variants of ductal carcinomas and other malignant tumours of the pancreas are rare.

- Perineural and vascular invasion is extremely common in ductal adenocarcinoma

\section{Recommendation - pathology}

- Proper recognition of variants of ductal carcinomas and other malignant tumours of the pancreas requires specialist pathological expertise (grade C).

\subsection{CLINICAL FEATURES AND DIAGNOSIS}

The three main symptoms of pancreatic cancer are pain, loss of weight, and jaundice. Nausea, anorexia, malaise, and vomiting are also common. Persistent back pain is associated with retroperitoneal infiltration and usually incurability. ${ }^{46}$ Severe and rapid weight loss are features that are usually also associated with unresectability. ${ }^{47}{ }^{48}$ Jaundice draws attention to ampullary tumours at a relatively early stage, which accounts for their higher resectability and may account for the better cure rates than for tumours further from the papilla. Conversely, jaundice in patients with carcinoma of the body or tail of the pancreas is usually caused by hepatic or hilar metastases and therefore indicates inoperability. Some $5 \%$ of patients with pancreatic cancer will have developed diabetes mellitus within the previous two years ${ }^{49}$ and recent onset diabetes in older patients may therefore serve as a warning sign. As noted above, recent onset of diabetes mellitus without predisposing features is associated with an increased risk of diagnosis of pancreatic cancer. Acute and chronic pancreatitis are also possible presentations of pancreatic cancer as $5 \%$ of cancer patients will present with 
an atypical attack of acute or subacute pancreatitis. ${ }^{50}$ In the absence of another recognised aetiology for an attack of pancreatitis, the possibility of an underlying carcinoma should be considered.

Migratory thrombophlebitis is rarely the first symptom of the disease. The same applies to the physical signs, apart from jaundice and a palpable gall bladder (Courvoisier's sign). Other findings are conspicuous by their absence. A palpable and fixed epigastric mass, ascites, or an enlarged supraclavicular lymph node (Virchow's node) are all signs of inoperability.

\section{Conclusions}

- In the majority of patients, the clinical diagnosis is fairly straightforward.

- There are no positive clinical features which clearly identify a patient group with potentially curable pancreatic or periampullary carcinoma.

- There are associated conditions, notably late onset diabetes mellitus and an unexplained attack of acute pancreatitis, which may point to an underlying pancreatic carcinoma.

- There are a number of clinical features (persistent back pain, marked, and rapid weight loss, abdominal mass, ascites, and supraclavicular lymphadenopathy) that usually indicate an incurable situation.

\section{Recommendations for diagnosis}

- The diagnosis of pancreatic cancer should be considered in patients with adult onset diabetes who have no predisposing features or family history of diabetes (grade B).

- Pancreatic cancer should be excluded during the investigation of patients who have had an unexplained episode of acute pancreatitis (grade B).

\subsection{INVESTIGATIONS}

There are no specific blood tests for the diagnosis of pancreatic carcinoma. Abnormal liver function tests cannot reliably distinguish biliary obstruction (of any cause) from hepatic metastases. The most useful initial investigation seems to be abdominal ultrasonography which can identify the pancreatic tumour, as well as dilated bile ducts, and will save considerable time and inconvenience if liver metastases are identified. The reported sensitivity of ultrasonography in the detection of pancreatic carcinoma is as high at $80-95 \% .^{51-53}$ The technique however, becomes less sensitive in evaluating the body and tail and provides less accurate staging information than other modalities, such as CT. ${ }^{54}{ }^{55}$ Technical difficulties with bowel gas compromise interpretation in 20$25 \%$ of subjects, ${ }^{56}$ and interobserver variation continues to be a problem..$^{53}$ Improvements in ultrasound technology, with inclusion of colour Doppler, may improve staging accuracy, particularly with respect to vascular invasion. ${ }^{57}$

CT and, more recently, MR imaging, both reliably demonstrate the primary tumour and evidence of extrapancreatic spread, particularly in the presence of liver metastases. $^{58-61}$ Contrast enhanced CT, particularly using helical scanners with arterial and portal phases of contrast enhancement, accurately predicts resectability in $80-90 \%$ of cases. $^{62-67}$ Assessment of local tumour extension with contiguous organ invasion, vascular involvement, hepatic metastases, and lymph node metastases correlate well with surgical findings in large tumours. CT is, however, much less accurate in identifying potentially resectable small tumours and where alternative diagnoses may need to be considered. ${ }^{68}$ Some centres believe that fine needle aspiration cytology under CT guidance is appropriate in these circumstances but this may be inadvisable if peritoneal seeding of cancer cells occurs, which might then eliminate the possibility of cure in otherwise potentially curable cases $^{69}$ (see section on tissue diagnosis). Early results suggest that spiral CT allied to multislice technology and three dimensional reconstruction may prove advantageous in the identification of small tumours and resectability. ${ }^{70-76} \mathrm{MR}$ imaging detects and predicts resectability with accuracies similar to CT.5976 77 MRCP provides detailed ductal images without the risk of ERCP induced pancreatitis and may clarify diagnostic uncertainty (chronic pancreatitis versus cancer) as well as being informative regarding intraductal tumours ${ }^{78-80}$ ). MRA can demonstrate vascular anatomy, and some have proposed a "one stop" investigation with MR, MRCP, and MRA. However, the value of this approach remains to be proven, and current practice is to obtain appropriate images with various techniques according to individual diagnostic questions and local expertise.

ERCP is important in the diagnosis of ampullary tumours by direct visualisation and biopsy. All other pancreatic tumours are detectable only if they impinge on the pancreatic duct so that small early cancers and those situated in the uncinate process can be missed by this technique. ERCP has the advantage of providing an opportunity to sample for cytology or histology and an important therapeutic modality via biliary stenting, to provide relief of jaundice and the associated symptom of pruritus.

Recent progress includes the use of endosonography (EUS) and the selective use of laparoscopy. EUS is highly sensitive in the detection of small tumours and invasion of major vascular structures ${ }^{81}{ }^{82}$ and can be used to avoid unnecessary surgery. EUS is superior to spiral CT, MR, or positron emission tomography in the detection of small tumours. ${ }^{83-87}$ Laparoscopy, including laparoscopic ultrasound, can detect occult metastatic lesions in the liver and peritoneal cavity not identified by other imaging modalities. ${ }^{88-90}$

Selective angiography has no place in establishing the diagnosis of pancreatic cancer but its use has been advocated by some authors as a means of detecting arterial anomalies and defining resectability. Most centres can now obtain this information non-invasively with CT or MR. While arterial anomalies are present in about a third of all patients undergoing pancreatic resection, this is nearly always an aberrant right hepatic artery, supplied from the superior mesenteric artery, and is detected at operation as pulsation posterior to the bile duct. This is easily recognisable and can be confirmed by intraoperative ultrasonography. Similarly, angiography is an unreliable method of predicting unresectability, with an overall predictive value in one recent series of only $61 \% .{ }^{91}$

The workup of patients with suspected pancreatic cancer should logically focus initially on establishment of the diagnosis and an assessment of the patient's fitness to undergo potentially curative treatment. In selected patients, further investigation involves tumour staging and the assessment of local resectability.

\section{Conclusions}

- Neither endosonography nor laparoscopic ultrasonography is widely available in the UK. Expertise and further evaluation of these techniques requires development. 
Recommendations for investigation and staging

- Clinical presentation suggesting cancer of the pancreas should lead without delay to ultrasound of the liver, bile duct, and pancreas (grade B).

- When the diagnosis of pancreatic malignancy is suspected from clinical symptoms and/or abdominal ultrasound findings, the selective use of CT, ERCP, and/ or MR, including MRCP and occasionally MRA, will accurately delineate tumour size, infiltration, and the presence of metastatic disease in the majority of cases (grade B).

- Where available, endosonography and/or laparoscopy with laparoscopic ultrasonography may be appropriate in selected cases (grade B).

\subsection{TISSUE DIAGNOSIS}

Tissue can be obtained by a variety of methods. Aspiration or brushing of the duct systems at ERCP have high specificity but low sensitivity. ${ }^{92}$ Guided biopsy or fine needle aspiration cytology can also be performed under EUS guidance. ${ }^{93} 94$

The alternative approach involves a transperitoneal approach. This can be undertaken transcutaneously under ultrasound or CT guidance, or at the time of laparoscopy with either visual or ultrasound guidance. These techniques have high specificity with a low risk of procedure related complications. ${ }^{95-97}$

There are however two concerns regarding transperitoneal techniques, particularly relevant to patients with small and potentially resectable tumours. Firstly, there is a risk of a false negative result. Failure to obtain histological confirmation of a suspected diagnosis of malignancy does not exclude the presence of a tumour, and should not delay appropriate surgical treatment. Secondly, there are concerns regarding tumour cell seeding along the needle track or within the peritoneum. ${ }^{98-100}$ Although the study by Warshaw ${ }^{69}$ showed that previous percutaneous biopsy significantly increased the incidence of positive peritoneal cytology in pancreatic tumours, most of the patients in this series who had positive cytology had advanced disease. In subsequent studies, fine needle aspiration did not increase the risk of positive peritoneal cytology. ${ }^{101}{ }^{102}$

The consequence of attempted resection without efforts to obtain a preoperative tissue diagnosis is that some patients will undergo resection for benign disease. This is probably the case in approximately $5 \%$ of all pancreaticoduodenal resections $^{103}$ and provided that pancreaticoduodenectomy can be undertaken with low morbidity and mortality, this represents an acceptable risk.

Given the above concerns, there seems little justification for transperitoneal biopsy in patients thought to have potentially resectable malignant lesions and those likely to benefit from surgery, even if benign disease is present. Conversely, reasonable efforts to obtain a tissue diagnosis should be made in patients selected to undergo palliative forms of therapy, to exclude variant tumour types which might have a better prognosis, and ensure patient eligibility for participation in trials evaluating new therapies.

\subsection{TREATMENT}

The treatment of pancreatic cancer has centred largely around palliative surgery undertaken to relieve symptoms, resectional surgery undertaken with intent to cure, and endoscopic or percutaneous biliary stenting to relieve jaundice. Chemotherapy and radiotherapy may also be used

\section{Recommendations - tissue diagnosis}

- Attempts should be made to obtain a tissue diagnosis during the course of investigative endoscopic procedures (grade C).

- Failure to obtain histological confirmation of a suspected diagnosis of malignancy does not exclude the presence of a tumour, and should not delay appropriate surgical treatment (grade C).

- Efforts should be made to obtain a tissue diagnosis in patients selected for palliative forms of therapy (grade C).

- Transperitoneal techniques to obtain a tissue diagnosis have limited sensitivity in patients with potentially resectable tumours and should be avoided in such patients (grade C).

as palliative treatments, as well as in an adjuvant setting in conjunction with surgery.

\subsection{Palliation by stent or surgery}

There have been three controlled trials of palliation of obstructive jaundice by stenting or surgical bypass but the results do not favour one method for use in all cases. ${ }^{104-106}$ The advantages of stenting include fewer immediate complications and shorter initial treatment time whereas surgery has better long term patency. Mortality rates at 30 days and median survival times are similar with the two techniques. It seems reasonable to reserve surgery for patients with good performance status and small tumours who are likely to survive longer than average, and to place a stent in patients with advanced tumours who are unlikely to survive longer than the usual patency time of the stent. The decision should also take account of the greater risk of early complications with the surgical approach.

We are not aware of any randomised comparison of expanding metal stents and bypass surgery for the relief of obstructive jaundice. There are reports of the use of expanding metal stents in duodenal obstruction but there is no convincing evidence that this approach offers a better outcome than surgical bypass.

\section{Recommendations for palliative drainage}

- Most patients requiring relief of obstructive jaundice will be adequately treated by placement of a plastic stent; surgical bypass may be preferred in patients likely to survive more than six months (grade A).

- Duodenal obstruction should be treated surgically (grade C).

\subsection{Stent insertion}

Endoscopic stent insertion into the biliary tree at the time of ERCP has been established for many years. ${ }^{107}$ A number of studies have shown that the endoscopic approach is associated with lower morbidity and procedure related mortality rates than the transhepatic approach, by minimising the risk of bile leaks and bleeding. ${ }^{108}$ Brush cytology and/ or biopsies can be taken from within the bile duct at the time of ERCP, prior to stenting. If the stricture cannot be negotiated with a catheter and guidewire system, a combined 
approach involving insertion of a transhepatic catheter and guidewire, which can be retrieved by the endoscopist, will allow successful stent placement in a group of patients where endoscopic stenting alone is unsuccessful. ${ }^{109}{ }^{110}$ However, in most centres such patients are now treated by percutaneous stent placement.

Modern techniques and equipment for percutaneous stenting with a self expanding metal stent are associated with fewer complications than percutaneous plastic stent placement and may be appropriate for patients who have better than average life expectancy but who are unsuitable for surgical palliation, after occlusion of a plastic stent, or when endoscopic stent placement has failed.

Insertion of biliary stents is associated with complications such as cholangitis and perforation. After stent insertion, the most important clinical problem is stent occlusion due to deposition of a bacterial biofilm and precipitation of biliary sludge within stents made of plastic. ${ }^{111}$ Recurrent jaundice usually indicates stent occlusion, rather than progressive disease. Such patients may need re-evaluation with a view to further stent placement. Occlusion is less problematic with self expanding metal stents, which open to a diameter of approximately $10 \mathrm{~mm}$. As the lumen of this type of stent is so large, biliary drainage is superior to that seen with plastic prostheses, so that blockage due to debris hardly ever occurs. Conversely, tumour ingrowth through the mesh can occur. The use of thin membranes to cover self expanding stents may minimise this problem. It would appear however that the average patency of metal stents in the distal bile duct is about twice that of polyethylene stents, the latter usually lasting for about four months. ${ }^{112}{ }^{113}$ Some selection of patients thought likely to survive for greater than this length of time might be used to identify those patients who should receive a self expanding metal stent. Because at least two thirds of patients with pancreatic cancer will be successfully palliated with a single stent ${ }^{106}$ and because the cost of a plastic prosthesis is approximately $3 \%$ or $4 \%$ of the cost of a self expanding metal prosthesis, both stent types should still be used appropriately.

Stenting is clearly best suited to patients with significant comorbid disease who are deemed unsuitable for surgery and those with proven widespread disease. While many clinicians view symptomatic gastrointestinal obstruction as a relative contraindication to biliary stenting, gastric outlet obstruction can be effectively palliated in some patients by a self expanding metal stent. ${ }^{114}$

\section{Recommendations for stenting}

- Endoscopic stent placement is preferable to transhepatic plastic stent placement (grade A).

- After failure of endoscopic stent placement, percutaneous placement of a self expanding metal stent, or a combined radiological/endoscopic approach, will increase the number of patients who can be successfully stented (grade B).

- Both plastic and self expanding metal stents are effective in achieving biliary drainage but require further development (grade A). Currently, the choice between these stents depends on clinical factors, local availability, and local expertise (grade C).

\subsection{Endoscopic stenting before resection}

The role of endoscopic stenting as a preliminary to attempted resection, in an attempt to reduce surgical morbidity and mortality related to jaundice, remains controversial. Retrospective data indicating that this reduces surgical morbidity ${ }^{115}$ have not been supported by a prospective randomised controlled trial although the numbers of patients studied were small. ${ }^{116}$ Several other non-randomised studies confirm that similar results can be obtained in jaundiced patients without relief of biliary obstruction, as in those who are operated on after relief of jaundice by endoscopic stenting. ${ }^{117-121}$ It is well established that preliminary external biliary drainage does not favourably influence hospital morbidity or mortality prior to pancreas resection in jaundiced patients. ${ }^{122-125}$

There is agreement based on anecdotal experience that surgical resection is made more difficult by the preoperative insertion of self expanding metal stents. This is attributed to the tissue reaction provoked by these stents, and the potential difficulty that may arise if the stent crosses the preferred line of bile duct division.

\section{Recommendation - preoperative stenting}

- There is little evidence of benefit from routine stenting of jaundiced patients before resection (grade A). However, if definitive surgery must be delayed more than 10 days, it is reasonable to obtain internal biliary drainage and to defer operation for 3-6 weeks to allow the jaundice to resolve (grade C).

- If a stent is placed prior to surgery, this should be of the plastic type and it should be placed endoscopically. Self expanding metal stents should not be inserted in patients who are likely to proceed to resection (grade C).

\subsection{Resectional surgery}

There is wide variation in resection rates and operative mortality rates in pancreatic cancer surgery. There is considerable evidence that operative mortality rates can be kept to low single figure values when undertaken in specialist centres. $^{126-128}$ These results contrast markedly with those obtained in the West Midlands where the resection rate in the two decades to 1976 and 1986 was only $2.6 \%$, with an operative mortality of $45 \%$ and $28 \%$ in the two periods. ${ }^{7} \mathrm{~A}$ similar study conducted by the New York State Department of Public Health demonstrated a clear correlation between caseload and surgical mortality. When surgeons performed less than nine resections annually, mortality was $16 \%$ compared with less than 5\% for surgeons performing more than forty cases per year. ${ }^{127}$ Similar relationships between hospital volume and mortality have been reported by other authors. ${ }^{130} 131$ A survey of 2.5 million complex surgical procedures showed a large inverse relationship between hospital volume and case mortality rates for pancreatic resection. ${ }^{132}$

In specialist centres, resectability rates are high at approximately $20 \%$, reflecting referral practices and case selection. ${ }^{126}{ }^{133-135}$ The most widely employed procedure is the Whipple pancreaticoduodenectomy, with a five year survival following resection of approximately $10 \%{ }^{136}{ }^{137}$ More radical approaches have been adopted, such as total pancreatectomy or portal vein excision, ${ }^{138-140}$ as well as more conservative approaches to include pylorus preservation in order to improve the quality of survival. ${ }^{141}{ }^{142}$ There are four acceptable types of operation: proximal pancreaticoduodenectomy with 
pylorus preservation; proximal pancreaticoduodenectomy with antrectomy (Kausch-Whipple); total pancreaticoduodenectomy; and left (distal) pancreatectomy.

\subsubsection{Proximal pancreaticoduodenectomy}

Large series have indicated that the pylorus preserving operation does not compromise long term survival figures compared with the standard Whipple's operation for carcinoma for the head of the pancreas. ${ }^{143}$ The potential drawbacks of the pylorus preserving operation are tumour involvement of the duodenal resection line and incomplete removal of regional lymph nodes. ${ }^{144} 145$ These risks can be obviated by patient selection so that the pylorus preserving operation is avoided in patients where there is proximal duodenal involvement or the tumour is close to the pylorus. ${ }^{146-148}$

The advantages of pylorus preservation have not been conclusively established but may include a reduction in post gastrectomy complications, a reduction in enterogastric reflux, and improved postoperative nutritional status and weight gain compared with the standard Whipple operation. ${ }^{145}{ }_{149-152}$

\subsubsection{Total pancreaticoduodenectomy}

This has no advantage in long term survival compared with Whipple's resection ${ }^{153} 154$ and has its own troublesome nutritional and metabolic sequelae. ${ }^{140} 155$ The procedure may be justified where there is diffuse involvement of the whole pancreas without evidence of spread.

\subsubsection{Left pancreatectomy}

This resection is indicated for lesions in the body and tail of the pancreas. Ductal carcinoma is seldom resectable in this location ${ }^{156}$ but this procedure may be appropriate for a variety of the other slow growing malignant tumours (see histopathology appendices).

\subsubsection{Radical and extended resections}

Modifications of these standard operations to include the portal vein and a block of lymphatic tissue around the origins of the coeliac and superior mesenteric arteries was proposed by Fortner and colleagues. ${ }^{157}$ In most centres, postoperative morbidity and mortality were higher than that encountered in the standard Whipple resection, although more recently a number of centres have reported mortality rates in the range $3-7 \% .{ }^{158-161}$ There are no data to indicate that this more radical approach is associated with increased survival. ${ }^{139} 162163$ A randomised controlled trial of extended versus standard lymphadenectomy also failed to demonstrate survival benefit. ${ }^{164}$

\subsubsection{Venous involvement}

Most surgeons agree that resection should not be undertaken with intent to excise tumours where there is clear preoperative evidence of venous encasement. It is believed that this situation is more hazardous for the patient, as a result of preoperative segmental portal hypertension, and some evidence exists that survival is not greatly different to that seen in patients who are not resected. ${ }^{165}$ Resection of the portal or superior mesenteric vein as a means of ensuring that resection with tumour free margins becomes feasible is appropriate if vein involvement is discovered during pancreaticoduodenectomy. This extension of the procedure does not increase operative morbidity or mortality ${ }^{166}$ and long term outcome is not affected by the need for vein resection. ${ }^{167}$

\section{Recommendations for surgical resection}

- Resectional surgery should be confined to specialist centres to increase resection rates and reduce hospital morbidity and mortality (grade B).

- Pancreatoduodenectomy (with or without pylorus preservation) is the most appropriate resectional procedure for tumours of the pancreatic head (grade B).

- Extended resections involving the portal vein or total pancreatectomy may be required in some cases but do not increase survival when carried out routinely (grade B).

- Resection in the presence of preoperative detection of portal vein encasement is rarely justified (grade C).

- Percutaneous biliary drainage prior to resection in jaundiced patients does not improve surgical outcome and may increase the risk of infective complications (grade A).

- Left sided resection (with splenectomy) is appropriate for localised carcinomas of the body and tail of the pancreas. Involvement of the splenic vein or artery is not in itself a contraindication to such resection (grade B).

\subsection{Palliative surgery}

A number of prospective randomised studies have been undertaken to compare palliative biliary drainage surgery with stenting, performed either endoscopically or by a transhepatic approach. In a direct comparison of plastic stent placement, procedure related morbidity and mortality rates were lower when the endoscopic route was used compared with the transhepatic route. ${ }^{108}$ Similarly, endoscopic stenting has a lower procedure related complication rate and mortality than surgical bypass, although this is at the expense of a higher risk of recurrent jaundice and a greater risk of gastric outlet obstruction. ${ }^{106}$ There is no recent published comparison of surgery and other methods of palliation: it is appropriate to consider surgery in low risk patients with potential for longer than average survival. Operative risk can be assessed using scoring systems, ${ }^{168-170}$ and the absence of an acute phase protein response has been shown in one study to be associated with longer survival. ${ }^{171}$ These features may help select patients for surgical palliation. While these procedures can be carried out by laparoscopic, as well as by open, means there are no data at present to indicate superiority of either approach.

A variety of bypasses have been employed. Relief of jaundice is more reliably attained when the bile duct is used rather than the gall bladder. ${ }^{172}{ }^{173}$ Addition of a duodenal bypass when there is gastric outflow obstruction does not increase operative risk. ${ }^{174}{ }^{175}$ Approximately 17\% of patients treated by biliary bypass alone subsequently require a gastroenterostomy. ${ }^{173}$ Prophylactic gastrojejunostomy decreases the incidence of late gastric outlet obstruction. ${ }^{176}$

\section{Recommendations for palliative surgery}

- Duodenal bypass should be used during palliative surgery (grade A).

- Biliary bypass should be constructed with the bile duct in preference to the gall bladder (grade B). 


\subsection{Non-surgical therapies}

The objectives of radiotherapy and chemotherapy in pancreatic cancer may be considered under three headings: (1) neoadjuvant or adjuvant therapy-therapy given prior to, during, or after surgery where the aim is to improve survival; (2) in the management of locally advanced disease, not amenable to surgical therapy; and (3) metastatic disease where the primary objective is palliation and prolongation, where possible, of a symptom free life.

\subsubsection{Adjuvant and neoadjuvant treatments}

\subsubsection{Adjuvant therapy}

A prospective randomised controlled study of adjuvant chemoradiation (5-fluorouracil (5-FU) for six days and $40 \mathrm{~Gy}$ of radiation followed by maintenance chemotherapy with 5-FU) after pancreaticoduodenectomy conducted by the Gastrointestinal Tumour Study Group ${ }^{177}$ demonstrated a survival advantage for multimodal therapy compared with resection alone. However, the total number of patients in this trial was only 43 , and because of slow postoperative recovery, $24 \%$ of the patients in the adjuvant chemoradiation arm did not begin chemoradiation until more than 10 weeks after surgery.

Two other randomised controlled trials have examined the role of postoperative chemoradiation therapy. An EORTC study of pancreatic and ampullary cancers found no benefit on survival for patients treated with radiation and 5-FU in a chemoradiation protocol similar to the GITSG study but without maintenance chemotherapy. ${ }^{178}$ The European Study Group for Pancreatic Cancer (ESPAC) reported a large trial (ESPAC-1) of 546 patients which compared adjuvant chemoradiotherapy with or without maintenance chemotherapy (5-FU with folinic acid) against no treatment. ${ }^{179}$ This showed no benefit for chemoradiotherapy and a probable survival advantage for prolonged chemotherapy after resection. Specific analysis according to resection margin status also failed to show any benefit for chemoradiotherapy but with the same proportional benefit for chemotherapy ${ }^{180} \mathrm{~A}$ further study is in progress to compare adjuvant 5-FU with folinic acid, gemcitabine, and no adjuvant therapy (ESPAC-3 trial).

A survival advantage was also demonstrated for adjuvant chemotherapy (5-FU, doxirubicin, mitomycin C) in another randomised controlled trial. Median survival was 23 months in 30 patients randomised to receive adjuvant therapy compared with 11 months in 31 patients treated with surgery alone. ${ }^{181}$ However, 46 additional patients were ineligible for the study following surgery and the toxicity of chemotherapy was significant. Only one third of the patients allocated actually received all six planned cycles of chemotherapy. This study is open to criticism of selection bias for protocol entry, selecting such therapy for patients who recover rapidly from surgery and have good performance status. Other studies have shown broadly similar effects without clear evidence of survival benefit. ${ }^{137182} 183$ At present, adjuvant therapy is not considered standard therapy. Further studies are planned or in progress, which should provide additional data regarding the potential benefits of adjuvant therapies.

\subsubsection{Neoadjuvant therapy}

An alternative strategy is to give non-surgical therapies before or during surgery. At present, reported studies rely on external beam radiotherapy or chemoradiation and are nonrandomised. These studies suggest that there may be an improvement in locoregional control but no significant improvement in survival. ${ }^{184-191}$ Neoadjuvant therapy remains investigational in pancreatic cancer.

\subsubsection{Intraoperative radiotherapy}

At present, no centre in the UK is using intraoperative radiotherapy. Despite some reports from centres with access to the appropriate equipment, there is at present no evidence of benefit with this technique to support its development in the UK.

\subsubsection{Combined therapy for locally advanced disease}

Patients with locally advanced non-metastatic disease have a median survival of 6-10 months. Reports of treatment without a control group provide no useful evidence to judge efficacy. However, improved median survival in a study of 64 such patients was demonstrated with a combination of external beam radiotherapy plus 5-FU compared with radiotherapy alone ( 10.4 versus 6.3 months, respectively) ${ }^{192} ; 5-\mathrm{FU}$ has remained the mainstay of chemoradiotherapy since then. ${ }^{193}$

To control metastases outside the radiation field, chemoradiotherapy has been combined with maintenance chemotherapy. Two GITSG studies ${ }^{194} 195$ and an Eastern Cooperative Oncology Group (ECOG) trial ${ }^{196}$ showed no survival benefit for chemoradiotherapy and maintenance chemotherapy with a variety of agents. Overall, the results are not convincingly better than for chemotherapy alone.

\subsubsection{Chemotherapy for non-resectable localised, metastatic, or recurrent disease}

Patients with metastatic disease have a limited survival of 3-6 months, dependent on the extent of disease and performance status. Many patients will not wish or be suitable for anticancer therapy. Well motivated patients with good performance status may gain psychological benefit from palliative chemotherapy; increased duration of survival has been shown in a few trials. ${ }^{197-199}$ The best objective response rates historically were achieved with 5-FU and mitomycin C. ${ }^{200}$ Chemotherapy regimens that use 5 -FU based doublet or triplet therapies have tended to be associated with greater toxicity without any survival advantage. ${ }^{201}$ However, since the introduction of gemcitabine the scene appears to be changing.

Gemcitabine is a deoxycitidine analogue that has been extensively evaluated, including in a randomised trial against bolus 5-FU. ${ }^{202}$ Patients treated with gemcitabine achieved modest but significant improvements in response rate and survival. There was also evidence of improvement in disease related symptoms, including a clinical benefit response (based on pain control, performance status, and weight gain) in $24 \%$ of gemcitabine treated patients, as opposed to $5 \%$ with 5-FU. This was the pivotal trial used to obtain licensing of gemcitabine. A recent NICE evaluation concluded that gemcitabine may be considered as a treatment option for patients with advanced or metastatic adenocarcinoma of the pancreas and a Karnofsky performance score of 50 or more, where firstline chemotherapy is to be used. If chemotherapy is to be used in patients with pancreatic adenocarcinoma, gemcitabine appears to be the agent of choice. ${ }^{203}$ There are now numerous phase II and phase III studies of doublet and triplet regimens that include gemcitabine as one of the active agents. $^{204}$

There remains continued interest in fluoropyrimidines, as seen in several studies of protracted venous infusion 5-FU and the development of orally active agents (including capecitabine (Xeloda), ZD9331, and Tegafur) as well as other antimetabolites (including raltitrexed (Tomudex) and pemetrexed (Alimta, LY231514)). Maisey and colleagues ${ }^{205}$ randomised patients to protracted venous infusion of 5-FU with or without mitomycin $\mathrm{C}$. The response rate was significantly higher in the combination arm $(17.6 \%$ and $8.4 \%$, 
respectively) and toxicities in both arms were mild but the difference in response rates did not translate into a significant difference in median survival (6.5 $v 5.1$ months, respectively). Cancer Research UK has recently launched the Gem-Cap Trial which will compare gemcitabine with or without capecitabine in a large phase III study in advanced pancreatic cancer.

\subsubsection{Other treatment approaches}

Pancreatic tumours contain sex hormone receptors. Suggestion of a survival benefit for tamoxifen has however not been confirmed in a randomised study. ${ }^{206}$ Metalloproteinase inhibitors such as marimastat have shown considerable promise, both as a single agent and in combination with gemcitabine, ${ }^{207} 208$ but their clinical utility has not been supported by a larger study ${ }^{209}$ benefit with any of these at present.

\section{Recommendations}

- Adjuvant or neoadjuvant therapies in conjunction with surgery should only be given in the context of a clinical trial (grade A).

- If chemotherapy is used for palliation, gemcitabine single agent treatment is recommended (grade A).

- Therapy with novel treatments should only be offered to patients within clinical trials (grade C).

\subsection{OTHER ASPECTS OF MEDICAL MANAGEMENT \\ 10.1 Relief of pancreatic pain}

Pain is a common presenting feature and in patients with advanced disease can be intolerable, providing a major therapeutic challenge. Various factors are thought to produce pancreatic pain, including increased parenchymal pressure secondary to ductal obstruction, neural infiltration, superimposed pancreatic inflammation, and associated biliary stenosis. ${ }^{210}$ The World Health Organisation analgesic ladder recommends three steps, from non-opioids, to opioids for mild to moderate pain, and then to opioids for moderate to severe pain. A variety of measures have been proposed to alleviate pancreatic pain in addition to oral and parenteral analgesics. Adjunctive approaches include pancreatic ductal decompression by endoscopic and surgical means..$^{210} 211$ Percutaneous, laparoscopic, or open ablation of the coeliac ganglia using $5 \%$ phenol or $50 \%$ ethanol produces effective palliation of pain in approximately $70 \%$ of patients. ${ }^{173}$ 212-214 The technique is most effective when used early rather than late in the course of disease and does reduce the consumption of other analgesics. ${ }^{212} 214$ Thoracoscopic division of the splanchnic nerves has also been described as an effective method. ${ }^{215} 216$

Pancreatic pain may be palliated by external beam radiotherapy, particularly when this recurs after coeliac plexus blockade. ${ }^{173}$ While the survival benefit of chemoradiation compared with chemotherapy alone is questionable, phase II studies typically report temporary pain relief in as many as $40-80 \%$ of patients. ${ }^{217} 218$

\subsection{Nutritional aspects of care}

\subsubsection{Pancreatic enzyme supplements}

Compared with untreated patients, patients with advanced pancreatic cancer who are given pancreatic enzyme supplements enjoy a better quality of life and improved symptom score. ${ }^{219}$

\subsubsection{Lipid supplements}

There is some evidence that lipid supplements with unsaturated fats, such as fish oil, may reduce weight loss and cachexia, and may prolong survival. ${ }^{220} 221$

\subsection{Palliative and supportive care}

There is good evidence that dying patients and their families benefit from the specialist attention which can be provided by palliative care units ${ }^{222}$ and hospices. ${ }^{223}$ In addition to pain, depression is a common problem in pancreatic cancer patients $^{224}{ }^{225}$ which may require treatment in its own right.

\section{Recommendations for medical management}

- Patients should have access to palliative medicine specialists (grade C).

- Pain relief should be achieved using a progressive analgesic ladder (grade B).

- Neurolytic coeliac plexus block is effective for the treatment and prevention of pain. Its use should be considered at the time of palliative surgery, or by a percutaneous or endoscopic approach in non-surgical patients (grade A).

- Chemoradiation should be considered for severe pain (grade B).

- Pancreatic enzyme supplements should be used to maintain weight and increase quality of life (grade A).

- Attention to dietary intake, and the use of specific nutritional supplements, may improve well being (grade B)

\subsection{ORGANISATION OF SERVICES}

The NHS Executive Evidence "Improving outcomes in upper gastrointestinal cancers" was published early in 2001. ${ }^{226} \mathrm{~A}$ key recommendation is the establishment of cancer centres and units, the former providing surgery for pancreatic cancers and dealing with population bases of between two and four million.

For a variety of reasons not all pancreatic centres are currently capable of offering a complete range of services to deal with all patients. Provision of effective services will require cancer units as well as specialist centres. It is acknowledged that appropriate service reconfiguration will require time and interim local arrangements will remain necessary, reflecting existing resource allocations.

\subsection{Cancer units}

Such units require sufficient diagnostic and therapeutic facilities to establish a likely diagnosis, assess the patient's overall level of fitness to withstand potentially curative forms of treatment, and provide appropriate therapeutic facilities to ensure that adequate symptom palliation can be achieved.

It is accepted that in some cancer units a specialist pancreatic surgeon with appropriate training and experience to justify resectional surgery may be available and may be required to continue to provide this service until service reconfiguration can be achieved. Provision of pancreatic resection in such cancer units should continue only with the approval of the Regional Upper Gastro-Intestinal and/or Hepato-Biliary-Pancreatic Cancer Network Group. 
The minimum requirements for a cancer unit are:

- An integrated system of clinical care involving medical and surgical gastroenterology, clinical oncology, radiology, and pathology.

- Adequate radiological facilities to establish a diagnosis and the likely stage of disease. This should include abdominal ultrasound and a whole body imaging technique (CT or MRI). Guided biopsy techniques should be available for patients considered not suitable for surgical resection.

- Therapeutic facilities should include both endoscopic and radiological biliary stenting and, at least on an interim basis, facilities for surgical palliation.

- A variety of ancillary services are required, including palliative care, acute and chronic pain services, and clinical nutrition.

Local cancer units should provide guidance to primary health care physicians to ensure adequate patient referral. The following patient groups merit general practitioner referral to a local cancer unit:

- Obstructive jaundice.

- Unexplained weight loss.

- Unexplained gastrointestinal bleeding or iron deficiency anaemia thought to be of gastrointestinal origin in the absence of an upper gastrointestinal or colorectal cause.

- Unexplained upper abdominal or back pain.

- Unexplained steatorrhoea.

- "Idiopathic" acute pancreatitis (no gall stones, no alcohol) in patients over 50 years of age.

- Unexplained diabetes in patients over 50 years of age (no family history, obesity, or steroids).

It can be anticipated that such a unit should be capable of providing effective palliation for $70-80 \%$ of patients in whom the diagnosis of pancreatic cancer is made. The implication is that $20-30 \%$ of patients will require referral to specialist centres.

\subsection{Specialist centres}

Specialist centres are justified for three main reasons. Existing data indicate that hospital mortality related to surgical resection is related to operative experience and volume. If it is accepted that approximately $20 \%$ of patients will benefit from resection, then from current epidemiological information, each year a centre would carry out 20 resections per million of population. Concentration of cases to achieve these numbers will be vital in the UK in future to provide adequate training for surgeons in upper gastrointestinal surgery. The Regional Cancer Network Group plan must ensure the timely establishment of the Regional Pancreas Tumour Centre based on a minimum of two million population that will undertake all pancreatic cancer resections in accordance with the National plans.

Specialist centres require all of the services provided at cancer units with further additions. These are:

- Facilities for precise pretreatment staging of disease with particular emphasis on assessment of resectability. These should include the majority of the following: spiral or multislice CT, MRI, endoscopic ultrasonography, laparoscopic ultrasonography.

- Increased therapeutic resources, including expertise in radiological and endoscopic intervention and adequate surgical expertise for pancreatic resections.

- Additional services in histopathology (see pathology reporting), intensive care, palliative care, and oncology.
- Facilities for the organisation and conduct of local, national, and international trials, evaluating new modalities for diagnosis and treatment as well as involvement in basic science research in pancreatic cancer.

\subsection{AUDIT AND AUDIT STANDARDS}

Comprehensive clinical audit is essential. The performance of an effective audit process includes the following:

- Accurate demographic information on all diagnosed cases.

- Duration of symptoms till first consultation.

- Duration from first consultation to referral to local cancer unit.

- Duration from date of referral to date of treatment.

- Accurate information on stage of disease involving the use of standardised histopathological assessments.

- Treatments received (the time from initial to definitive treatment should not exceed six weeks).

- Duration of hospital stays.

- Complications of treatment.

- Duration of survival.

- Quality of life assessments using validated instruments (for example, EORTC QLQ-C30) with a pancreatic cancer specific module (for example, QLQ PAN26) should be applied to all patients involved in prospective clinical trials.

The following standards are appropriate for clinical audit:

- Cancer units should respond to general practitioner requests within two weeks and specialist centres should respond to cancer unit referrals within a further two weeks.

- A full minimum data set should be available for all patients.

- Resection rate in unselected patients should be more than $10 \%$, and associated hospital mortality rate after pancreatic resection should be less than $10 \%$.

\subsection{OTHER ORGANISATIONAL ISSUES}

Because of wide variations in the extent of services between hospitals in the UK it remains difficult, in some aspects of practice, to provide firm guidelines which are immediately applicable. The following, however, represent elements which both cancer units and specialist centres should be capable of achieving for patients with pancreatic adenocarcinoma.

- Joint assessments involving appropriate physicians, surgeons, oncologists, radiologists, histopathologists, specialist nurses, research personnel, and representatives from intensive care, palliative care, and nutritional services.

- Appropriate high dependency, intensive care, and anaesthetic facilities for pancreatic surgery. An adequately equipped and staffed system of graduated care is important. Anaesthetists and intensivists at consultant level should be familiar with the specialised surgery involved, in particular the nature and duration of surgery, which can be prolonged.

\subsection{HISTOPATHOLOGICAL REPORTING}

This is of greatest importance in patients who have undergone surgical resection. Accurate and reproducible information demands an understanding of histological typing, grading, staging, and clinical residual tumour classification.

The appendix includes the minimum data set required for histopathological reporting for carcinomas arising from pancreas, bile duct, and ampulla of Vater. 


\section{Recommendation for pathological reporting}

- The minimum data set proposed by the Royal College of Pathologists (see appendix for details) should be used for reporting histological examination of pancreatic resection specimens (grade C).

\subsection{ACKNOWLEDGEMENTS}

\section{Contributors}

D Alderson, CD Johnson, JP Neoptolemos, CC Ainley, MK Bennett, F Campbell, RM Charnley, PG Corrie, SJ Falk, AK Foulis, RI Hall, CN Hacking, CW Imrie, RH Kennedy, AN Kingsnorth, R Lendrum, AJ Longstaff, JMcK Manson, CJ Mitchell, RCG Russell, WEG Thomas. Prepared by a Writing Committee established by the Pancreatic Section of the British Society of Gastroenterology, with the participation of the Pancreatic Society of Great Britain and Ireland, the Association of Upper Gastrointestinal Surgeons of Great Britain and Ireland, the Royal College of Pathologists, and the Special Interest Group for Gastro-Intestinal Radiology.

\section{Members of the drafting committee}

Professor D Alderson, Professor of Gastrointestinal Surgery, Bristol Royal Infirmary; Mr CD Johnson, Reader in Surgery, Southampton General Hospital; Dr CC Ainley, Consultant Gastroenterologist, Newham General Hospital, London; Dr MK Bennett, Consultant Pathologist, Freeman Hospital, Newcastle upon Tyne; Dr D Breen, Consultant Radiologist, Southampton General Hospital; Mr RM Charnley, Consultant Surgeon, Freeman Hospital, Newcastle upon Tyne; Dr F Campbell, Consultant Pathologist, Royal Liverpool Hospital, Liverpool; Dr PG Corrie, Consultant Medical Oncologist, Addenbrooke's Hospital, Cambridge; Dr SJ Falk, Consultant Oncologist, Bristol Oncology Centre; Dr AK Foulis, Consultant Pathologist, Glasgow Royal Infirmary; Dr CN Hacking, Consultant Radiologist, Southampton General Hospital; Mr RI Hall, Consultant Surgeon, Derby City Hospital; Professor CW Imrie, Consultant Surgeon, Glasgow Royal Infirmary; Dr R Lendrum, Consultant Physician, Freeman Hospital, Newcastle upon Tyne; Dr AJ Longstaff, Consultant Radiologist, Frenchay Hospital; Mr RH Kennedy, Consultant Surgeon, Yeovil District Hospital; Professor AN Kingsnorth, Professor of Surgery, Derriford Hospital, Plymouth; Mr JMcK Manson, Consultant Surgeon, Singleton Hospital, Swansea; Dr CJ Mitchell, Consultant Physician, Scarborough Hospital; Professor JP Neoptolemos, Professor of Surgery, Royal Liverpool University Hospital, Liverpool; Mr RCG Russell, Consultant Surgeon, the Middlesex Hospital, London; Mr WEG Thomas, Consultant Surgeon, Royal Hallamshire Hospital, Sheffield.

\subsection{APPENDIX}

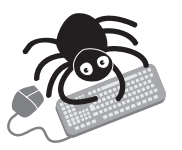

For details of the minimum data set proposed by the Royal College of Pathologists, see hitp:// www.rcpath.org/index.asp?PagelD = 254 .

Conflict of interest: None declared.

\subsection{REFERENCES}

1 Office of Population Censuses and Surveys. Cancer mortality, England and Wales 1911-1970. In: Studies on medical and population subjects. London: HMSO, 1975: No 29. Grade III

2 Office for National Statistics. Registration of cancer diagnosis in 1999. London: HMSO, 2002. Grade III

3 Muir C, Waterhouse J, Mack T. Cancer incidence in five continents, volume V. Lyons: International Agency for Research on Cancer, 1987:IARC Scientific Publication No 88. Grade III

4 Morgan RGH, Wormsley KG. Progress report: cancer of the pancreas. Gut 1977;18:580-96. Grade III

5 Gordis L, Gold EB. Epidemiology of pancreatic cancer. World J Surg 1984;8:808-21. Grade III

6 Allen-Mersh TG, Earlam RJ. Pancreatic cancer in England and Wales: a surgeon's look at epidemiology. Ann R Coll Surg Engl 1986;68:154-8. Grade III

7 Bramhall SR, Allum WH, Jones AG, et al. Treatment and survival in 13560 patients with pancreatic cancer, and incidence of the disease, in the West Midlands: an epidemiological study. Br J Surg 1995;82:111-15. Grade III
8 Fernandez E, La Vecchia C, Porta M, et al. Trends in pancreatic cancer mortality in Europe, 1955-1989. Int J Cancer 1994;57:786-92. Grade III

9 Parkin DM, Bray Fl, Devesa SS. Cancer burden in the year 2000. The global picture. Eur J Cancer 2001;37(suppl 8):4-66. Grade III

10 Surveillance, Epidemiology and End Results Program. http:// seer.cancer.gov/faststats/html/inc_pancreas.html (accessed March 2005). Grade III

11 Best EW. A Canadian study of smoking and health. Ottawa: Department of National Health and Welfare, 1966. Grade III

12 Hammond EC. Smoking in relation to the death rates of one million men and women. NCl Monogr 1966;19:126. Grade III

13 Cederlof R, Friberg L, Hrubec Z, et al. The relationship of smoking: a ten-year follow-up in a probability sample of 55000 Swedish subjects, age 18-69. Stockholm: Karolinska Institute, 1975:parts 1/2. Grade III

14 Doll R, Peto R, Wheatley K, et al. Mortality in relation to smoking: 40 years of observations on male British doctors. BMJ 1994;309:901-11. Grade III

15 Hirayama T. Changing patterns of cancer in Japan with special reference to the decrease in stomach cancer mortality. In: Hiatt $\mathrm{HH}$, Watson JD, Winston JA, eds. Origins of human cancer, vol 4. Cold Spring Harbor: Cold Spring Harbor Laboratory, 1977:55. Grade III

16 Mack TM, Yu MC, Hanisch R, et al. Pancreas cancer and smoking, beverage consumption, and past medical history. J Natl Cancer Inst 1986;76:49-60. Grade Ilb

17 Falk RT, Pickle LW, Fontham ET, et al. Lifestyle risk factors for pancreatic cancer in Lovisiana: a case control study. Am J Epidemiol 1988; 128:324-36. Grade Ilb

18 Ghadirian P, Simard A, Baillargeon J. Tobacco, alcohol and coffee and cancer of the pancreas. A population-based case-control study in Quebec, Canada. Cancer 1991;67:2664-70. Grade Ilb

19 Talamini G, Bassi C, Falconi M, et al. Alcohol and smoking as risk factors in chronic pancreatitis and pancreatic cancer. Dig Dis Sci 1999;44:1303-11. Grade III

20 Coughlin SS, Calle EE, Patel AV, et al. Predictors of pancreatic cancer mortality among a large cohort of United States adults. Cancer Causes Control 2000;11:915-23. Grade Ilb

21 Löwenfels AB, Maisonneuve P, Cavallini G, et al. Pancreatitis and the risk of pancreatic cancer. N Engl J Med 1993;328:1433-7. Grade III

22 Gullo L, Pezzilli R, Morselli-Labate AM. Italian Pancreatic Cancer Study Group. Diabetes and the risk of pancreatic cancer. N Engl J Med 1994;331:81-4. Grade IIb

23 Bansal P, Sonnenberg A. Pancreatitis is a risk factor for pancreatic cancer. Gastroenterology 1995; 109:247-57. Grade Ilb

24 Löwenfels AB, Maisonneuve P, DiMagno EP, et al. Hereditary pancreatitis and the risk of pancreatic cancer. J Natl Cancer Inst 1997;89:442-6. Grade III

25 Howes N, Wong T, Greenhalf W, et al. Pancreatic cancer risk in hereditary pancreatitis in Europe. Digestion 2000;61:300. Grade III

26 Tersmette AC, Petersen GM, Offerhaus GJ, et al. Increased risk of incident pancreatic cancer among first-degree relatives of patients with familial pancreatic cancer. Clin Cancer Res 2001;7:738-44. Grade Ilb

27 Silverman DT, Schiffman M, Everhart J, et al. Diabetes mellitus, other medical conditions and familial history of cancer as risk factors for pancreatic cancer. Br J Cancer 1999;80:1830-7. Grade llb

28 Murphy KM, Brune KA, Griffin C, et al. Evaluation of candidate genes MAP2K4, MADH4, ACVR1B, and BRCA2 in familial pancreatic cancer: deleterious BRCA2 mutations in 17\%. Cancer Res 2002;62:3789-93. Grade III

29 Hahn SA, Greenhalf W, Ellis I, et al. BRCA2 germ line mutations in familial pancreatic carcinoma. J Natl Cancer Inst 2003;95:214-21. Grade III

30 Bergman W, Watson $\mathrm{P}$, de Jong J, et al. Systemic cancer and the FAMMM syndrome. Br J Cancer 1990:61:932-6. Grade III

31 Lynch HT, Fusaro RM. Pancreatic cancer and the familial atypical multiple mole melanoma (FAMMM) syndrome. Pancreas 1991;6:127-31. Grade III

32 Giardiello FM, Brensinger JD, Tersmette AC, et al. Very high risk of cancer in familial Peutz-Jeghers syndrome. Gastroenterology 2000;1 19:1447-53. Grade III

33 Lynch HT, Smyrk TC, Watson P, et al. Genetics, natural history, tumor spectrum, and pathology of hereditary nonpolyposis colorectal cancer-an updated review. Gastroenterology 1993;104:1535-49. Grade IV

34 Phelan CM, Lancaster JM, Tonin P, et al. Mutation analysis of the BRCA2 gene in 49 site-specific breast cancer families. Nat Genet 1996;13:120-2. Grade III

35 Offerhaus GJ, Giardiello FM, Krush AJ, et al. The risk of upper gastrointestinal cancer in familial adenomatous polyposis. Gastroenterology 1992;102:1980-2. Grade III

36 Whelan AJ, Bartsch D, Goodfellow PJ. A familial syndrome of pancreatic carcinoma and melanoma with a mutation in the CDKN2 tumor suppressor gene. N Engl J Med 1995;333:975-7. Grade III

37 Ulrich $\mathbf{C}$ and members of the Third International Symposium on Hereditary Diseases. Pancreatic cancer in hereditary pancreatitis-Consensus guidelines for prevention, screening, and treatment. Pancreatology 2001;1:412-41. Grade IV

38 EUROPAC. http://www.liv.ac.uk/surgery/europac.html (accessed March 2005).

39 Jagelman DG, decosse JJ, Bussey HJR. Upper gastrointestinal cancer in familial adenomatous polyposis. Lancet 1988;i:1149-51. Grade III

40 Spigleman AD, Williams CB, Talbot IC, et al. Upper gastrointestinal cancer in patients with familial adenomatous polyposis. Lancet 1989;ii:783-5. Grade III 
41 Spigelman AD, Talbot IC, Penna C, et al. Evidence for adenoma-carcinoma sequence in the duodenum of patients with familial polyposis. J Clin Pathol 1994;47:709-10. Grade III

42 Groves CJ, Saunders BP, Spigelman AD, et al. Duodenal cancer in patients with familial adenomatous polyposis (FAP): results of a 10 year prospective study. Gut 2002;50:636-41. Grade III

43 Solcia E, Capella C, Kloppel G, eds. Tumours of the pancreas. Washington DC: Armed Forces Institute of Pathology, 1997:262. Grade III

44 Cubilla AL, Fitzgerald PF. Morphological patterns of primary non-endocrine human pancreas carcinoma. Cancer Res 1975;35:2234-40. Grade III

45 Compagno J, Oertel JE. Mucinous cystic neoplasms of the pancreas with overt and latent malignancy (cystadenocarcinoma and cystadenoma). A clinicopathological study of 41 cases. Am J Clin Pathol 1978;69:573-80. Grade III

46 Trede M, Carter DC. Clinical evaluation and pre-operative assessment. In: Trede M, Carter DC, eds. Surgery of the pancreas. Edinburgh: Churchill Livingstone, 1993:423-31. Grade IV

47 Perez MM, Newcomer AD, Moertel CG, et al. Assessment of weight loss, food intake, fat metabolism, malabsorption, and treatment of pancreatic insufficiency in pancreatic cancer. Am Cancer Soc 1983;52:346-52. Grade III

48 Petrek JA, Sandberg WA, Bean PK, et al. Can survival in pancreatic adenocarcinoma be predicted by primary size or stage? Am Surg 1985;51:42-6. Grade III

49 Moossa AR, Levin B. The diagnosis of 'early' pancreatic cancer: the University of Chicago experience. Am Cancer Soc 1981;47:1688-97. Grade III

50 Gambil EF. Pancreatitis associated with pancreatic carcinoma: study of 26 cases. Mayo Clin Proc 1971;46:174. Grade III

51 Cotton PB, Lees WR, Vallon AG, et al. Grey-scale ultrasonography and endoscopic pancreatography in pancreatic diagnosis. Radiology 1980;134:453-9. Grade III

52 Taylor KJW, Buchin PJ, Viscomi GN, et al. Ultrasonographic scanning of the pancreas prospective study of clinical results. Radiology 1981;138:211-13. Grade Ilb

53 Karlson BM, Ekbom A, Lindgren PG, et al. Abdominal US for diagnosis of pancreatic tumor: prospective cohort analysis. Radiology 1999;213:107-11. Grade III

54 Freeny PC, Lawson L. Radiology of the pancreas. New York: SpringerVerlag, 1982. Grade III

55 Lees WR. Pancreatic ultrasonography. Clin Gastroenterol 1984;13:763-89. Grade III

56 Shmulewitz A, Teefey SA, Robinson BS. Factors effecting image quality and diagnostic efficacy in abdominal sonography: a prospective study of 140 patients. J Clin Ultrasound 1993;21:623-30. Grade III

57 Tomiyama T, Ueno N, Tano S, et al. Assessment of arterial invasion in pancreatic cancer using color doppler ultrasonography. Am J Gastroenterol 1996;91:1410-16. Grade III

58 Steiner E, Stark DD, Hahn PF, et al. Imaging of pancreatic neoplasms: comparison of MRI and CT. Am J Roentgenol 1989;152:487-91. Grade IIb

59 Vellet AD, Romano W, Bach DB, et al. Adenocarcinoma of the pancreatic ducts: comparative evaluation with CT and MRI imaging at 1.5T. Radiology 1992; 183:87-95. Grade Ilb

60 Warshaw AL, del Castillo CF. Pancreatic carcinoma. N Engl J Med 1992;326:455-65. Grade III

61 Hollett MD, Brooke Jeffrey R Jnr, Nino-Murcia M, et al. Dual phase helical CT of the liver; value of arterial phase scans in the detection of small (less than $1.5 \mathrm{~cm}$ ) malignant hepatic neoplasms. AJR Am J Roentgenol 1995; 164:879-84. Grade III

62 Freeny PC, Marks WM, Ryan JA, et al. Pancreatic ductal adenocarcinoma: diagnosis and staging with dynamic CT. Radiology 1988;166:125-33. Grade III

63 Freeny PC, Traverso LW, Ryan JA. Diagnosis and staging of pancreatic adenocarcinoma with dynamic computer tomography. Am J Surg 1993; 165:600-6. Grade III

64 Fuhrman GM, Charnsangavej C, Abbruzzese JL, et al. Thin section contrast enhanced computed tomography accurately predicts the resectability of malignant pancreatic neoplasms. Am J Surg 1994;167:104-11. Grade III

65 Choi BI, Chung MJ, Han JK, et al. Detection of pancreatic adenocarcinoma: relative value of arterial and late phases of spiral CT. Abdom Imaging 1997;22:199-203. Grade III

66 Chong M, Freeny PC, Schmiedl UP. Pancreatic arterial anatomy. Depiction with dual phase helical CT. Radiology 1998;208:537-42. Grade III

67 McCarthy MJ, Evans J, Sagar G, et al. Prediction of resectability of pancreatic malignancy by computed tomography. Br J Surg 1998;85:320-5. Grade III

68 Griffanti-Bartoli. Malignant tumours in the head of the pancreas and periampullary region. Anti Cancer Res 1994;14:657-66. Grade III

69 Warshaw AL. Implications of peritoneal cytology for staging of early pancreatic cancer. Am J Surg 1991;161:26-30. Grade llb

70 Dupuy DE, Costello P, Eccer CP. Spiral CT of the pancreas. Radiology 1992;183:815-18. Grade lla

71 Yoshimi F, Hasegawa H, Koizumi S, et al. Application of three-dimensional spiral computed tomographic angiography to pancreatoduodenectomy for cancer. Br J Surg 1995;82:116-17. Grade III

72 Coley SC, Strickland NH, Walker JD, et al. Spiral CT and the pre-operative assessment of pancreatic carcinoma. Clin Radiol 1997;52:24-30. Grade III

73 Vedantham S, Lu DSK, Reber HA, et al. Small peripancreatic veins: improved assessment in pancreatic cancer patients using thin-section pancreatic phase helical CT. AJR Am J Roentgenol 1998;170:377-83. Grade III
74 Novick SL, Fishman EK. Three-dimensional CT angiography of pancreatic carcinoma: role in staging extent of disease. AJR Am J Roentgenol 1998;170:139-43. Grade III

75 Rodgers PM, Ward J, Baudouin CJ, et al. Dynamic contrast enhanced MR imaging of the portal venous system: Comparison with X-ray angiography. Radiology 1994;191:741-5. Grade III.

76 Megibow AJ, Zhou XH, Rotterdam H, et al. Pancreatic adenocarcinoma: CT versus MR imaging in the evaluation of resectability - report of the Radiology Diagnostic Oncology Group. Radiology 1995;195:327-32. Grade Ila.

77 Ichikawa T, Haradome H, Hachiya J, et al. Pancreatic ductal adenocarcinoma: preoperative assessment with helical CT versus dynamic gadolinium MR imaging. Radiology 1997;202:655-62. Grade Ilb

78 Bret PM, Reinhold C. Magnetic resonance cholangiopancreatography. Endoscopy 1997;29:472-86. Grade III

79 Reuther G, Kiefer B, Tuchmann A, et al. Imaging studies of pancreaticobiliary duct diseases with single shot MR cholangiopancreatography. AJR Am J Roentgenol 1997;168:453-59. Grade III

80 Vitellas KM, Keogan MT, Spritzer CE, et al. MR cholangiopancreatography of bile and pancreatic duct abnormalities with emphasis on single-shot fast spin-echo technique. Radiographics 2000;20:1108-12. Grade III

81 Rosch T, Lightdale CJ, Botet JF, et al. Endosonographic localization of pancreatic endocrine tumours. N Engl J Med 1992;326:1721-6. Grade III

82 Palazzo L, Roseau G, Gayet B, et al. Endoscopic ultrasonography in the diagnosis and staging of pancreatic adenocarcinoma. Results of a prospective study with comparison to ultrasonography and CT scan Endoscopy 1993;25:143-50. Grade Ilb

83 Muller MF, Meyenberger C, Bertschinger P, et al. Pancreatic tumours: Evaluation with endoscopic US, CT and MR imaging. Radiology 1994;190:745-51. Grade Ilb

84 Howard TJ, Chin AC, Streib EW, et al. Value of helical computed tomography, angiography and endoscopic ultrasound in determining resectability of periampullary carcinoma. Am J Surg 1997; 174:237-41 Grade IIb

85 Legmann P, Vignaux O, Dousset B, et al. Pancreatic tumors: Comparison of dual phase helical CT and endoscopic sonography. AJR Am J Roentgenol 1998;170:1315-22. Grade Ilb

86 Midwinter MJ, Beveridge CJ, Wilsdon JB, et al. Correlation between spiral computed tomography, endoscopic ultrasonography and findings at operation in pancreatic and ampullary tumours. Br J Surg 1999;86:189-93. Grade IIb

87 Mertz HR, Sechopoulos P, Delbeke D, et al. EUS, PET and CT scanning for evaluation of pancreatic adenocarcinoma. Gastrointest Endosc 2000;52:367-71. Grade Ilb

88 Warshaw AL, Tepper JE, Shipley WU. Laparoscopy in the staging and planning of therapy for pancreatic cancer. Am J Surg 1986;151:76-9. Grade III

89 Murugiah M, Patterson-Brown S, Windsor JA, et al. Early experience of laparoscopic ultrasonography in the management of pancreatic carcinoma. Surg Endosc 1993;7:177-81. Grade III

90 John TG, Greig JD, Carter DC, et al. Carcinoma of the pancreatic head and peri-ampullary region: tumour staging with laparoscopy and laparoscopic ultrasonography. Ann Surg 1995;221:136-64. Grade llb

91 Murugiah M, Windsor JA, Redhead DN, et al. The role of selective visceral angiography in the management of pancreatic and peri-ampullary cancer World J Surg 1993;17:796-800. Grade Ilb

92 Kurzawinsk TI, Deery AL, Davidson BR. Diagnostic value of cytology for biliary stricture. Br J Surg 1993;80:414-21. Grade Ilb

93 Tio TL, Sie LH, Tytgat GNJ. Endosonography and cytology in diagnosing and staging pancreatic body and tail carcinoma. Dig Dis Sci 1993;38:59-64. Grade III

94 Chang KJ, Nguyen P, Erickson RA, et al. The clinical utility of endoscopic ultrasound guided fine-needle aspiration in the diagnosis and staging of pancreatic carcinoma. Gastrointest Endosc 1997;45:387-93. Grade III

95 Jennings PE, Donald JJ, Coral A, et al. Ultrasound guided co-biopsy. Lancet 1989;1:1369-71. Grade III

96 Parsons L, Palmer $\mathrm{CH}$. How accurate is fine needle biopsy in malignant neoplasia of the pancreas? Radiology 1989;173:586. Grade III

97 Brandt KR, Charbonneau JW, Stephens DH, et al. CT and US guided biopsy of the pancreas. Radiology 1993;187:99-104. Grade III

98 Ferrucci JT, Wittenberg J, Margolics MN, et al. Malignant seeding of the tract after thin needle aspiration biopsy. Radiology 1979;130:345-6. Grade III

99 Rashleigh-Bilcher HJC, Russell RCG, Lees WR. Cutaneous seeding of pancreatic carcinoma by fine needle aspiration biopsy. Br J Radiol 1986;59:182-3. Grade III

100 Lees WR. Imaging diagnosis of pancreatic cancer. Curr Pract Surg 1994;6:143-6. Grade III

101 Leach SD, Rose JA, Lowy AM, et al. Significance of peritoneal cytology in patients with potentially resectable adenocarcinoma of the pancreatic head. Surgery 1995; 1 18:472-8. Grade Ilb

102 Merchant NB, Conlon KC, Saigo P, et al. Positive peritoneal cytology predicts unresectability of pancreatic adenocarcinoma. J Am Coll Surg 1999:188:421-6. Grade III

103 Smith CD, Behrns KE, van Heerden JA, et al. Radical pancreaticoduodenectomy for misdiagnosed pancreatic mass. Br J Surg 1994;81:585-9. Grade III

104 Shepherd HA, Royle G, Ross APR, et al. Endoscopic biliary endoprosthesis in the palliation of malignant obstruction of the distal common bile duct: a randomised trial. Br J Surg 1988;75:1166-8. Grade Ib

105 Andersen JR, Soren SM, Kruse A, et al. Randomised trial of endoscopic prosthesis versus operative bypass in malignant obstructivwe jaundice. Gut 1989;30:1132-5. Grade Ib 
106 Smith AC, Dowsett JF, Russell RCG, et al. Randomised trial of endoscopic stenting versus surgical bypass in malignant low bile duct obstruction. Lancet 1994;344: 1655-60. Grade Ib

107 Cotton PB. Progress report: ERCP. Gut 1977;18:316-41. Grade IV

108 Speer AG, Cotton PB, Russell RCG, et al. Randomized trial of endoscopic versus percutaneous stent insertion in malignant obstructive jaundice. Lancet 1987;ii:57-62. Grade Ib

109 Robertson DF, Hacking CN, Birch S, et al. Experience with combined purcutaneous and endoscopic approaches to stent insertion in malignan obstructive jaundice. Lancet 1987;ii: 1449-52. Grade III

110 Dowsett JF, Vaira D, Hatfield ARW, et al. Endoscopic biliary therapy using the combined percutaneous and endoscopic technique. Gastroenterology 1989:96:1180-6. Grade III

111 Leung JWC, Ling TRW, Kung JLS, et al. The role of bacteria in the blockage of biliary stents. Gastro Endosc 1988;34:19-22. Grade III

112 Davids PH, Groen AK, Rauws EA, et al. Randomised trail of self-expanding metal stents versus polyethylene stents for distal malignant biliary obstruction. Lancet 1992;340:1488-92. Grade Ib

113 O'Brien S, Hatfield ARW, Craig PI, et al. A three year follow-up of self expanding metal stents in the endoscopic palliation of long-term survivors with malignant biliary obstruction. Gut 1995:36:618-21. Grade III

114 Soetikno RM, Lichtenstein DR, Vandervoort J. Palliation of malignant gastric outlet obstruction using an endoscopically placed wall stent. Gastrointest Endosc 1998;47:267-70. Grade III

115 Klinkenbiil JHG, Jeekel J, Schmitz PIM, et al. Carcinoma of the pancreas and peri-ampullary region: palliation versus cure. Br J Surg 1993;80:1575-8. Grade III

116 Lai ECS, Mok FPT, Fan ST, et al. Preoperative endoscopic drainage for malignant obstructive jaundice. Br J Surg 1994;81:1195-8. Grade lb

117 Povoski SP, Karpeh MS Jr, Conlon KC, et al. Preoperative biliary drainage: impact on intraoperative bile cultures and infectious morbidity and mortality after pancreaticoduodenectomy. J Gastrointest Surg 1999;3:496-505. Grade III

118 Martignoni ME, Wagner M, Krahenbuhl L, et al. Effect of preoperative biliary drainage on surgical outcome after pancreatoduodenectomy. Am J Surg 2001;181:52-9. Grade III

119 Sewnath ME, Birimohun RS, Rauws EA, et al. The effect of preoperative biliary drainage on postoperative complications after pancreaticoduodenectomy. J Am Coll Surg 2001;192:726-34. Grade III

120 Pisters PW, Hudec WA, Hess KR, et al. Effect of preoperative biliary decompression on pancreaticoduodenectomy-associated morbidity in 300 consecutive patients. Ann Surg 2001;234:47-55. Grade III

121 Marcus SG, Dobryansky M, Shamamian P, et al. Endoscopic biliary drainage before pancreaticoduodenectomy for periampullary malignancies. J Clin Gastroenterol 1998;26:125-9. Grade III

122 Hatfield ARW, Tobias R, Terblanche J, et al. Pre-operative external biliary drainage in obstructive jaundice. Lancet 1982;2:896-9. Grade Ib

123 McPherson GAD, Benjamin IS, Hodgson HJF, et al. Pre-operative percutaneous transhepatic biliary drainage: The results of a controlled trial. $\mathrm{Br} J$ Surg 1984;71:371-5. Grade Ib

124 Pitt HA, Gomes AS, Louis JF, et al. Does pre-operative percutaneous biliary drainage reduce operative risk or reduce hospital cost? Surgery 1985;201:545-53. Grade Ib

125 Smith RC, Pooley M, George CRP, et al. Pre-operative percutaneous transhepatic internal drainage in obstructive jaundice: A randomized controlled trial examining renal function. Surgery 1985;97:641-8. Grade lb

126 Trede M, Schwall G, Saeger HD. Survival after pancreatoduodenectomy. 118 consecutive resections without an operative mortality. Ann Surg 1990;211:447-58. Grade III

127 Cameron JL, Pitt HA, Yeo CJ, et al. One hundred and forty-five consecutive pancreaticoduodenectomies without mortality. Ann Surg 1993;217:430-8. Grade III

128 Neoptolemos JP, Russell RCG, Bramhall S, et al. For the UK Pancreatic Cancer Group. Low mortality following resection for pancreatic and periampullary tumours in 1026 patients: UK survey of specialist pancreatic units. Br J Surg 1997;84:1370-6. Grade III

129 Lieberman MD, Kilburn H, Lindsey M, et al. Relation of peri-operative deaths to hospital volume among patients undergoing pancreatic resection for malignancy. Ann Surg 1995;222:638-45. Grade III

130 Glasgow RE, Mulvihill SJ. Hospital volume influences outcome in patients undergoing pancreatic resection for cancer. West J Med 1996; 165:294-300. Grade III

131 Sosa JA, Bowman HM, Gordon TA, et al. Importance of hospital volume in the overall management of pancreatic cancer. Ann Surg 1998;228:429-38. Grade III

132 Birkmeyer JD, Siewers AE, Finlayson EV, et al. Hospital volume and surgical mortality in the United States. N Engl J Med 2002;346:1 128-37. Grade lla

133 Bodner E. Achievements of tumor surgery in tumors of the pancreas. Langenbecks Arch Chir 1988;2(suppl):133-8. Grade III

134 Funovics JM, Karner J, Pratschner T, et al. Current trends in the management of carcinoma of the pancreatic head. Hepatogastroenterology 1989;36:450-5. Grade III

135 Cameron JL, Crist DW, Sitzmann JV, et al. Factors influencing survival after pancreaticoduodenectomy for pancreatic cancer. Am J Surg 1991;161:120. Grade III

136 Russell RCG. Surgical resection for cancer of the pancreas. Baillieres Clin Gastroenterol 1990;4:889. Grade IV

137 Livingston EH, Welton ML, Reber HA. Surgical treatment of pancreatic cancer: The United States experience. Int J Pancreatol 1991;9:153-7. Grade III
138 Ihse I, Lilja P, Arnesjo B, et al. Total pancreatectomy for cancer: an appraisal of 65 cases. Ann Surg 1977;186:675. Grade III

139 Fortner JG. Regional pancreatectomy for cancer of the pancreas, ampulla and other related sites. Tumour staging and results. Ann Surg 1984:199:418. Grade III

140 van Heerden JA. Pancreatic resection for carcinoma of the pancreas: Whipple versus total pancreatectomy-an institutional perspective. World J Surg 1984;8:880. Grade III

141 Braasch JW, Deziel DJ, Rossi RL, et al. Pyloric and gastric preserving pancreatic resection. Ann Surg 1986;204:41 1-18. Grade III

142 Grace PA, Pitt HA, Longmire WP. Pancreatoduodenectomy with pylorus preservation for adenocarcinoma of the head of the pancreas. Br J Surg 1986:73:647. Grade III

143 Pitt HA. Curative treatment for pancreatic neoplasms: standard resection. Surg Clin North Am 1995;75:891-904. Grade III

144 Sharp KW, Ross CB, Halter SA, et al. Pancreatoduodenectomy with pyloric preservation for carcinoma of the pancreas: a cautionary note. Surgery 1989; 105:645-53. Grade III

145 Zerbi A, Balzano G, Patuzzo R, et al. Comparison between pyloruspreserving and Whipple pancreatoduodenectomy. $\mathrm{Br} J$ Surg 1995;82:975-79. Grade Ilb

146 Watanapa P, Williamson RCN. Resection of the pancreatic head with or without gastrectomy. World J Surg 1995;19:403-9. Grade IV

147 Nakao A, Harada A, Nonami T, et al. Lymph node metastasis in carcinoma of the head of the pancreas region. Br J Surg 1995;82:399-402. Grade III

148 Roder JD, Stein HJ, Hüttl W, et al. Pylorus-preserving vs standard pancreatico-duodenectomy: an analysis of 110 pancreatic and periampullary carcinomas. Br J Surg 1992;79:152-5. Grade Ilb

149 Braasch JW. Pancreaticoduodenal resection. Curr Probl Surg 1988;25:323-63. Grade III

150 Fink AS, DeSouza LR, Mayer EA, et al. Long term evaluation of pylorus preservation during pancreaticoduodenectomy. World J Surg 1988; 12:663-70. Grade III

151 Williamson RCN, Bliouras N, Cooper MJ, et al. Gastric emptying and enterogastric reflux after conservative and conventional pancreatoduodenectomy. Surgery 1993;114:82-6. Grade Ilb

152 McLeod RS, Taylor BR, O'Conner BI, et al. Quality of life, nutritional status and gastrointestinal hormonal profile following the Whipple procedure. Am J Surg 1995; 169:179-85. Grade III

153 Edis AJ, Kierman PD, Taylor WF. Attempted curative resection of ductal carcinoma of the pancreas. Mayo Clin Proc 1980;55:531. Grade IV

154 Herter FP, Cooperman AM, Ahlborn TN, et al. Surgical experience with pancreatic and peri-ampullary cancer. Ann Surg 1982; 195:274. Grade III

155 Andren-Sandberg A, lhse I. Factors influencing survival after total pancreatectomy in patients with pancreatic cancer. Ann Surg 1983; 198:605. Grade III

156 Johnson CD, Schwall G, Flechtenmacher J, et al. Resection for adenocarcinoma of the body and tail of the pancreas. $\mathrm{Br} J$ Surg 1993;80:1177-9. Grade III

157 Fortner JG, Kim DK, Cubilla AL, et al. Regional pancreatectomy. En bloc pancreatic, portal vein and lymph node dissection. Ann Surg 1977; 186:42-50. Grade III

158 Tsuchiya R, Tsunoda T, Ishida T, et al. Resection for cancer of the pancreas the Japanese experience. Baillieres Clin Gastroenterol 1990;4:931. Grade IV

159 Hanyu F, Susuki M, Imaizumi T. Whipple operation for pancreatic carcinoma: Japanese experiment. In: Beger HG, Buchler MW Malfertheiner $P$, eds. Standards in pancreatic surgery. Berlin: SpringerVerlag, 1993:646. Grade IV

160 Gall FP, Zirngibl H. Cancer of the pancreas-extensive lymph node dissection. In: Beger HG, Buchler MW, Malfertheiner P, eds. Standards in pancreatic surgery. Berlin: Springer-Verlag, 1993:654. Grade IV

161 Satake K, Nishiwaki H, Yokomatsu H, et al. Surgical curability and prognosis for standard versus extended resection for Tl carcinoma of the pancreas. Surg Gynecol Obstet 1992;175:259. Grade lla

162 Sindelar WF. Clinical experience with regional pancreatectomy for adenocarcinoma of the pancreas. Arch Surg 1989;124:127-132. Grade III

163 Brooks JR. Cancer of the pancreas. In: Brooks JR, ed. Surgery of the pancreas. Philadelphia: WB Saunders Co, 1983:263. Grade IV

164 Pedrazzoli S, Di Carlo VI, Dionigi R, et al. Standard versus extended lymphadenectomy associated with pancreaticoduodenectomy in the surgical treatment of adenocarcinoma of the head of the pancreas. Ann Surg 1998;228:508-17. Grade Ib

165 Launois B, Franci J, Bardaxoglou E, et al. Total pancreatectomy for ductal adenocarcinoma of the pancreas with special reference to resection of the portal vein and multicentri cancer. World J Surg 1993;17:122-7. Grade III

166 Leach SD, Lee JE, Charnsangave JC, et al. Survival following pancreaticoduodenectomy with resection of the superior mesenteric-portal vein confluence for adenocarcinoma of the pancreatic head. Br J Surg 1988;85:611-17. Grade III

167 Sasson AR, Hoffman JP, Ross EA, et al. En bloc resection for locally advanced cancer of the pancreas: is it worthwhile? J Gastrointest Surg 2002;6: 147-58. Grade III

168 Blamey SL, Fearon KCH, Gilmour WH, et al. Prediction of risk in biliary surgery. Br J Surg 1983;70:535-8. Grade III

169 Lai EC, Chu KM, Lo CY, et al. Surgery for malignant obstructive jaundice: analysis of mortality. Surgery 1992;112:891-6. Grade III

170 van den Bosch RP, van der Schelling GP, Klinkenbiil JHG, et al. Guidelines for the application of surgery and endoprostheses in the palliation of obstructive jaundice in advanced cancer of the pancreas. Ann Surg 1994;219:18-24. Grade III 
171 Falconer JS, Fearon $\mathrm{KCH}$, Ross JA, et al. The acute phase protein response and duration of survival in patients with pancreatic cancer. Cancer 1995;75:2077-82. Grade III

172 Sarfeh IJ, Rypins EB, Jakwatz JG, et al. A prospective randomised clinical investigation of cholecystoenterostomy and choledochoenterostomy. Am J Surg 1988;155:411-14. Grade Ib

173 Watanapa P, Williamson RCN. Surgical palliation for pancreatic cancer: developments during the past two decades. Br J Surg 1992;79:8-20. Grade IV

174 Sarr MG, Gladden ME, Beart RW Jr, et al. Role of prophylactic gastroenterostomy for unresectable peri-ampullary carcinoma. Surg Gyneol Obstet 1980;151:794-6. Grade III

175 Sarr MG, Cameron JL. Surgical management of unresectable carcinoma of the pancreas. Surgery 1992;91:123-33. Grade III

176 Lillemoe KD, Cameron JL, Hardacre JM, et al. Is prophylactic gastrojejunostomy indicated for unresectable periampullary cancer? A prospective randomized trial. Ann Surg 1999;230:322-8. Grade lb

177 Gastrointestinal Tumour Study Group. Further evidence of effective adjuvant combined radiation and chemotherapy following curative resection of pancreatic cancer. Cancer 1987;59:2006-10. Grade lb

178 Klinkenbijl JH, Jeekel J, Sahmoud T, et al. Adjuvant radiotherapy and 5fluorouracil after curative resection of cancer of the pancreas and periampullary region: phase III trial of the EORTC gastrointestinal trac cancer cooperative group. Ann Surg 1999;230:776-82. Grade Ib

179 Neoptolemos JP, Dunn JA, Stocken DD, et al. Adjuvant chemoradiotherapy and chemotherapy in resectable pancreatic cancer: a randomised controlled trial. Lancet 2001;358:1576-85. Grade lb

180 Neoptolemos JP, Stocken DD, Dunn JA, et al. Influence of resection margins on survival for patients with pancreatic cancer treated by adjuvant chemoradiation and/or chemotherapy within the ESPAC-1 randomized controlled trial. Ann Surg $2001 ; 234: 758-68$. Grade III

181 Bakkevold KE, Arnesjo B, Dahl O, et al. Adjuvant combination chemotherapy (AMF) following radical resection of carcinoma of the pancreas and papilla of Vater-results of a controlled, prospective, randomised multicentre study. Eur J Cancer 1993;5:698-703. Grade Ib

182 Splinter TA, Obertop H, Kok TC, et al. Adjuvant chemotherapy after resection of adenocarcinoma of the peri-ampullary region and the head of the pancreas. A non-randomized pilot study. J Cancer Res Clin Oncol 1989;155:200-2. Grade Ilb

183 Baumel H, Huguier M, Manderscheid JC, et al. Results of resection for cancer of the exocrine pancreas: a study from the French Association of Surgery. Br J Surg 1994;81:102-7. Grade III

184 Hiraoka T. Extended radical resection of cancer of the pancreas with intra operative radiotherapy. Baillieres Clin Gastroenterol 1990;4:985-93. Grade III

185 Zerbi A, Fossati V, Parolini D, et al. Intra-operative radiation therapy adjuvant to resection in the treatment of pancreatic cancer. Cancer 1994:73:2930-35. Grade Ilb

186 Pilepich MV, Miller HH. Preoperative irradiation in carcinoma of the pancreas. Cancer 1980;46:1945-9. Grade III

187 Ishikawa O, Ohhigashi H, Teshima T, et al. Clinical and histopathological appraisal of preoperative irradiation for adenocarcinoma of the pancreatoduodenal region. J Surg Oncol 1989:40:143-51. Grade III

188 Weese JL, Nussbaum ML, Paul AR, et al. Increased resectability of locally advanced pancreatic and peri-ampullary carcinoma with neoadjuvant chemoradiotherapy. Int J Pancreatol 1990;7:177-85. Grade III

189 Breslin TM, Hess KR, Harbison DB, et al. Neoadjuvant chemoradiotherapy for adenocarcinoma of the pancreas: treatment variables and survival duration. Ann Surg Oncol 2001;8:123-32. Grade III

190 White R, Lee C, Anscher M, et al. Preoperative chemoradiation for patients with locally advanced adenocarcinoma of the pancreas. Ann Surg Oncol 1999;6:38-45. Grade III

191 Snady H, Bruckner H, Cooperman A, et al. Survival advantage of combined chemoradiotherapy compared with resection as the initial treatment of patients with regional pancreatic carcinoma. An outcomes trial. Cancer 2000:89:314-27. Grade III

192 Moertel CG, Childs DS, Reitemeier RJ, et al. Combined 5-fluorouracil and super voltage radiation therapy of locally unresectable gastrointestinal cancer. Lancet 1969;2:865-7. Grade Ib

193 Boz G, De Paoli A, Innocente R, et al. Radiotherapy and continuous infusion 5 -fluorouracil in patients with nonresectable pancreatic carcinoma. Int J Radiat Oncol Biol Phys 2001;51:736-40. Grade III

194 Gastrointestinal Tumour Study Group. Treatment of locally unresectable carcinoma of the pancreas: comparison of combined modality therapy (chemotherapy plus radiotherapy) to chemotherapy alone. J Natl Cancer Inst 1984;80:751. Grade Ib

195 Gastrointestinal Tumour Study Group. Radiation therapy combined with Adriamycin or 5-fluourouracil in the treatment of locally unresectable pancreatic carcinoma. Cancer 1985;56:2563. Grade lb

196 Klaassen DJ, Maclntyre JM, Catton GE, et al. Treatment of locally unresectable cancer of the stomach and pancreas: a randomized comparison of 5-fluorouracil alone with radiation plus concurrent and maintenance 5-fluorouracil-an Eastern Cooperative Oncology Group study. J Clin Oncol 1985;3:373-8. Grage Ib

197 Mallinson CN, Rake MD, Cocking JB, et al. Chemotherapy in pancreatic cancer: results of a controlled prospective randomised, multicentre trial. BMJ 1980;281:1589-91. Grade Ib
198 Palmer KR, Kerr M, Knowles $G$, et al. Chemotherapy prolongs survival in inoperable pancreatic cancer. Br J Surg 1994;81:882-5. Grade Ib

199 Glimelius B, Hoffman K, Sjödén P-O, et al. Chemotherapy improves survival and quality of life in advanced pancreatic and biliary cancer. Ann Oncol 1996:7:593-600. Grade Ib

200 Haycox A, Lombard M, Neoptolemos JP, et al. Current treatment and optimal patient management in pancreatic cancer. Aliment Pharmacol Ther 1998; 12:49-964. Grade la

201 Cullinan S, Moertel CG, Wieand HS, et al. A phase III trial on the therapy of advanced pancreatic carcinoma. Evaluations of the Mallinson regimen and combined 5-fluorouracil, doxorubicin, and cisplatin. Cancer 1990;65:2207-2. Grade Ib

202 Burris HA, Moore MJ, Andersen J, et al. Improvements in survival and clinical benefit with gemcitabine as first-line therapy for patients with advanced pancreas cancer: A randomised trial. $J$ Clin Oncol 1997; 15:2403-13. Grade Ib

203 NICE (National Institute for Clinical Excellence). Guidance on the use of gemcitabine for pancreatic cancer May 2001. http://www.nice.org.uk/ article.asp?a $=16790$ (accessed March 2005). Grade la

204 Ko AH, Tempero MA. Current and future strategies for combined-modality therapy in pancreatic cancer. Curr Oncol Rep 2002;4:202-12. Grade IV

205 Maisey N, Chau I, Cunningham D, et al. Multicenter randomized phase III trial comparing protracted venous infusion (PVI) fluorouracil (5-FU) with PVI 5 -FU plus mitomycin in inoperable pancreatic cancer. J Clin Oncol 2002;20:3130-6. Grade Ib

206 Bakkevold KE, Pattersen A, Ames JB, et al. Tamoxifen therapy in unresectable adenocarcinoma of the pancreas and the papilla of Vater. Br J Surg 1990;77:725-30. Grade Ib

207 Evans JD Stark A, Johnson CD, et al. A phase II trial of marimastat in advanced pancreatic cancer. Br J Cancer 2001;85:1865-70. Grade lb

208 Carmichael J, et al. A phase lb study of concurrent administration of marimastat and gemcitabine in non-resectable pancreatic cancer. ASCO Proc 1998;17:232a. Grade III.

209 Bramhall SR, Rosemurgy A, Brown PD, et al. Marimastat as first-line therapy for patients with unresectable pancreatic cancer: a randomized trial. J Clin Oncol 2001; 19:3447-55. Grade Ib

210 Lichtenstein DR, Carr-Locke DL. Endoscopic palliation for unresectable pancreatic carcinoma. Surg Clin North Am 1995:75:969-88. Grade IV

211 Boyle TJ, Williamson RCN. Mini symposium - pancreatic cancer: bypass procedures. Curr Pract Surg 1994;6:154-60. Grade IV

212 Sharfman WH, Walsh TD. Has the analgesic efficacy of neurolytic celiac plexus block been demonstrated in pancreatic cancer pain. Pain 1990:41:267-71. Grade III

213 Lillemoe KD, Cameron JL, Kaufman HS, et al. Chemical splanchnicectomy in patients with unresectable pancreatic cancer. A prospective randomized trial. Ann Surg 1993;217:447-57. Grade Ib

214 Polati E, Finco G, Gottin L, et al. Prospective randomised double-blind trial of neurolytic coeliac plexus block in patients with pancreatic cancer. $\mathrm{Br} J$ Surg 1998;85:199-201. Grade Ib

215 Worsey J, Ferson PF, Keenan RJ, et al. Thoracoscopic pancreatic denervation for pain control in irresectable pancreatic cancer. $\mathrm{Br} J$ Surg 1993;80:1051-52. Grade III

216 Andren-Sandberg A, Zoucas E, Lillo-Gil R, et al. Thoracoscopic splanchnicectomy for chronic, severe pancreatic pain. Semin Laparosc Surg 1996;3:29-33. Grade III

217 Andre T, Balosso J, Louvet $\mathrm{C}$, et al. Combined radiotherapy and chemotherapy (cisplatin and 5-fluorouracil) as palliative treatment for localized unresectable or adjuvant treatment for resected pancreatic adenocarcinoma: results of a feasibility study. Int J Radiat Oncol Biol Phys 2000;46:903-11. Grade III

218 Shinchi $\mathrm{H}$, Takao S, Noma H, et al. Length and quality of survival after external-beam radiotherapy with concurrent continuous 5 -fluorouracil infusion for locally unresectable pancreatic cancer. Int J Radiat Oncol Biol Phys 2002;53:146-50. Grade Ib

219 Bruno MJ, Haverkort EB, Tijssen GP, et al. Placebo controlled trial of enteric coated pancreatin microsphere treatment in patients with unresectable cancer of the pancreatic head region. Gut 1998;42:92-6. Grade Ib

220 Barber MD, Ross JA, Voss AC, et al. The effect of an oral nutritional supplement enriched with fish oil on weight-loss in patients with pancreatic cancer. Br J Cancer 1999:81:80-6. Grade Ilb

221 Wigmore SJ, Ross JA, Falconer JS, et al. The effect of polyunsaturated fatty acids on the progress of cachexia in patients with pancreatic cancer. Nutrition 1996;12(suppl):S27-30. Grade Ilb

222 Hockley JM, Dunlop R, Davis RJ. Survey of distressing symptoms in dying patients and their families in hospital and the response to a symptom control team. BMJ 1988:296:1715-17. Grade Ilb

223 Brescia FJ. Specialized care of the terminally ill. In: DeVita VT, Hellman S, Rosenberg SA, eds. Cancer, principles and practice of oncology, 4th edn. Philadelphia: Lippincott, 1993:2501-8. Grade III

224 Fras I, Litin EM, Pearson JS. Comparison of psychiatric symptoms in carcinoma of the pancreas with those in some other intra-abdominal neoplasms. Am J Psychiatry 1967;123:1553-62. Grade Ilb

225 Holland JC, Korzun AH, Tross S, et al. Comparative psychological disturbance in patients with pancreatic and gastric cancer. Am J Psychiatry 1986;143:982-6. Grade Ilb

226 NHS Executive. Guidance on commissioning cancer services. Improving outcomes in upper gastrointestinal cancers. London: Department of Health, 2001. Grade IV 